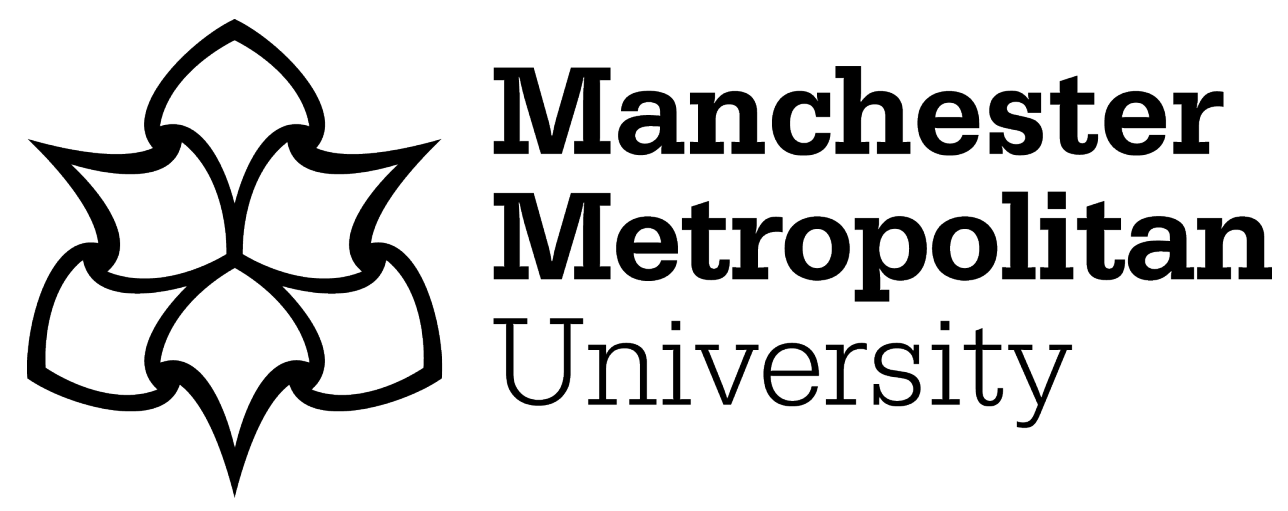

Stamou, Vasileios, Clerveaux, Rebecca, Stamou, Lelouda, Le Rocheleuil, Sarah, Berejnoi, Lucie, Romo, Lucia and Graziani, Pierluigi (2017) The therapeutic contribution of music in music-assisted systematic desensitization for substance addiction treatment: A pilot study. The Arts in Psychotherapy, 56. pp. 30-44. ISSN 0197-4556

Downloaded from: https://e-space.mmu.ac.uk/625447/

Version: Accepted Version

Publisher: Elsevier BV

DOI: https://doi.org/10.1016/j.aip.2017.07.002

Please cite the published version 


\title{
The therapeutic contribution of music in music-assisted systematic desensitization for substance addiction treatment: A pilot study.
}

\begin{abstract}
We previously reported that music-assisted systematic desensitization can counter-condition substance-related cues and reduce the implicated craving responses, as well as improve cognitive and psychopathological components of substance addiction. This follow-up study investigated the therapeutic contribution of listening to recorded New Age relaxing music in counterconditioning external substance-conditioned cues, as well as in the amelioration of everyday life craving reactivity, craving beliefs and depression. Twenty-one substance addicted individuals participated in a three-week randomized controlled trial consisting of two therapeutic sessions per week. Participants were randomly assigned to one of the two study groups, systematic desensitization combined with listening to New Age relaxing music recorded in individual MP3 devices, and systematic desensitization without music. Measurements of craving in response to external substance-conditioned cues, craving beliefs, everyday craving reactivity and depression took place at baseline, post-treatment and one month after the end of treatment. No significant group differences in the outcome measures were observed between both arms of the study but within group and time results suggest that listening to New Age relaxing music significantly enhances systematic desensitization and accounts for significant reductions of craving responses to external substance-conditioned cues and of craving beliefs associated with compulsive behaviour in the music group. Our study provides the first evidence on the potential therapeutic contribution of music to cue counterconditioning in substance addiction treatment. Further investigation on the capacity of music to increase the effectiveness of systematic desensitization seems warranted.
\end{abstract}

Key words: Music, Craving, Drugs, Alcohol, Addiction, Systematic desensitization 


\section{Introduction}

Among the contemporary social and medical problems, substance addiction ranks as one of the most devastating and costly and is nowadays considered to be a worldwide epidemic (Poznyak et al., 2013). Numerous theories have attempted to explain substance addiction. One of the most dominant addiction models of the past century was the disease model which posits that the main causes for addiction can be found in individual physiology and genetics (Hall, Carter, \& Forlini, 2015). However, as research studies have not succeeded in substantiating this model (Levy, 2013) new theories have been developed, such as the cognitive behavioural theory of addiction which argues that substance addiction is a learned behaviour that mainly takes place via association. Cognitive behavioural interventions have been widely employed for substance addiction treatment and have identified these associations as principal therapeutic targets in order to modify maladaptive behavioural patterns that promote substance use and pose a significant risk for relapse (Romo \& Graziani, 2015).

According to Pavlov (1927/1960), neutral cues can become conditioned if repeatedly paired with substance use (Myers \& Carlezon, 2010; Ramirez, Monti, \& Colwill, 2015) and elicit conditioned psychophysiological and behavioural responses that increase substanceseeking behaviours (Hone-Blanchet, Wensing, \& Fecteau, 2014). Cognitive behavioural therapy (CBT) considers situations that involve this kind of cues as high-risk for relapse and targets at providing individuals with substance use disorders (SUD) with alternative coping strategies so as to facilitate abstinence (Yokoyama et al., 2015). One of the main therapeutic techniques employed to this end is cue-exposure therapy, such as systematic desensitization, which focuses on extinguishing substance-conditioned cues and the implicated craving responses via unreinforced exposure (Hone-Blanchet et al., 2014). Cue-exposure interventions have been extensively investigated concerning their capacity to reduce craving 
and alter maladaptive behavioural responses to substance-conditioned cues but have produced contradictory findings (Hone-Blanchet et al., 2014; Manley, 2008; McHugh, Park, \& Weiss, 2014; Myers \& Carlezon, 2010; Romo \& Graziani, 2015). This led to the notion of cue counterconditioning, which proposes developing a new association with the cue instead of weakening the already existing one via unreinforced exposure, in order to learn a new behavioural response that will facilitate abstinence (Van Gucht, Baeyens, Hermans, \& Beckers, 2013; Van Gucht, Baeyens, Vansteenwegen, Hermans, \& Beckers, 2010).

Counterconditioning substance-related cues would entail an alternative external factor capable of inducing emotions of positive valence in order to counteract the negative psychophysiological effects of the conditioned cues and allow the reduction of the implicated craving responses. Of interest, it has been demonstrated that listening to relaxing or pleasant music can induce distinct emotions of positive valence (Brattico et al., 2011; Sammler, Grigutsch, Fritz, \& Koelsch, 2007; Salimpoor, Benovoy, Larcher, Dagher, \& Zatorre, 2011; Salimpoor, Benovoy, Longo, Cooperstock, \& Zatorre, 2009; Salimpoor et al., 2013; Schäfer \& Sedlmeier, 2010) via regulating the release of dopamine (Blum et al., 2010; Menon \& Levitin, 2005; Salimpoor et al., 2011) and endogenous opioids (Chanda \& Levitin, 2013), and by deactivating brain regions associated with negative affect (Blood \& Zatorre, 2001; Chanda \& Levitin, 2013). Importantly, this property of music has been suggested to counteract negative psychophysiological (Bernatzky, Presch, Anderson, \& Panksepp, 2011; Bradt \& Dileo, 2009; Labbe, Schmidt, Babin, \& Pharr, 2007; Nilsson, 2009; Nilsson, Unosson, \& Rawal, 2005; Sakamoto, Ando, \& Tsutou, 2013; Sarkamo et al., 2008) and cognitive states (Phipps, Carroll, \& Tsiantoulas, 2010; Salamon, Kim, Beaulieu, \& Stefano, 2003; Sarkamo et al., 2008), and facilitate the counterconditioning of cues associated with substance use during substance addiction treatment (Stamou, Chatzoudi, Stamou, Romo \& Graziani, 2016). 
In a recent study we investigated the effectiveness of music-assisted in vitro cueexposure therapy in counterconditioning substance-related cues. We demonstrated that listening to New Age relaxing music not associated with substance use combined with systematic desensitization may be capable of significantly reducing craving responses to substance-conditioned cues, and of facilitating the amelioration of cognitive and psychopathological components of substance addiction, such as permissive thoughts and depression symptoms (Stamou et al., 2016). In the context of that study and of the present study, new age relaxing music was defined as new age music that was characterized by slow stable tempo, soft dynamics, low level of volume, ambient sounds performed in synthesizers and sounds of nature, legato melodies, simple chord sequences, and the absence of lyrics and accented rhythmic patterns played by percussion. These musical features are considered as the common characteristics found in music perceived as relaxing by the listeners (Radocy \& Boyle, 2003) and the relaxation effect of the music was employed to facilitate counterconditioning substance-associated cues. Despite the positive findings of our recent study on the therapeutic usefulness of music-assisted cue exposure therapy in substance addiction treatment, the confounded design of the study did not allow investigating the potential superiority of music-assisted cue exposure treatment that focuses on cue counterconditioning over unreinforced cue exposure therapy that has been widely used in the past, nor to investigate the exact contribution of New Age relaxing music in the counterconditioning process. In the present study, we primarily aimed at demonstrating that music-assisted cue counterconditioning with the use of the same New Age relaxing music is more effective than unreinforced cue exposure in reducing craving responses to substance-conditioned cues, which were predefined as the primary outcome of the study. We hypothesized that listening to New Age relaxing music not formerly associated with substance use, combined with systematic desensitization can decrease craving responses to external substance-conditioned 
cues significantly more that systematic desensitization without music. The secondary objectives of the study were to investigate if music-assisted cue counterconditioning is more effective that unreinforced cue exposure in inducing positive changes on a) craving reactivity in everyday life, b) craving beliefs (overall craving beliefs, craving beliefs associated with compulsive behaviour, craving beliefs related with negative coping and craving beliefs linked with will power), and c) symptoms of depression, which were predefined as the secondary outcomes of the study.

\section{Materials and Methods}

This parallel randomized trial was approved by the Aix-Marseille University Ethics Committee and by the Commission of Informatics, Liberty and Data Protection in France. The study described in the context of this paper was conducted in the Psychotherapeutic Centre of Osny, the Clinic of Montevideo and the Therapeutic Community of Aubervilliers, in France.

\subsection{Research setting and participants}

Thirty-three substance addicted individuals who had been diagnosed with drug or alcohol use disorders according to the DSM-V criteria (American Psychiatric Association, 2013) and received regular treatment in the Psychotherapeutic Centre of Osny, the Clinic of Montevideo and the Therapeutic Community of Aubervilliers, declared an interest to participate in the study. According to the research protocol, individuals diagnosed with cooccurring psychosis, schizophrenia or uncontrolled bipolar disorder could not be included in the study due to the administration of medication that could modify the levels of craving. Such condition would impede the research protocol and potentially affect the results. 


\subsection{Procedure}

\subsubsection{Pre-treatment phase}

The researchers presented the research study to the directors and therapeutic teams of the three organizations who subsequently issued a call for participation in the study. An information group was arranged in each organization, during which the researchers fully explained the purpose, design and course of the study to prospective participants. It was clearly underscored that participation in the study was voluntary and participants could retire at any moment without any consequences for them and the treatment they received. Eighteen individuals diagnosed with alcohol use disorders and 15 individuals diagnosed with drug use disorders declared an interest to take part in the study (See Figure 1). Three participants met the non-inclusion criteria of the research protocol (two were diagnosed with comorbid psychoticism and one had experienced episodes of schizophrenia and suicidal ideation) and were not included in the study. Subsequently, 17 individuals diagnosed with alcohol use disorders and 13 individuals diagnosed with drug use disorders provided their written consent.

The sample randomization process took place in front of all participants via a draw. Each participant's name was written on a piece of paper and was randomly chosen so that participants were assigned to one of the following groups: a) fifteen participants for the Music-Assisted Systematic Desensitization group (MASD) who would receive six sessions of systematic desensitization combined with listening to New Age relaxing music recorded in individual MP3 devices, in addition to their standard treatment, and b) fifteen participants for the systematic desensitization group (SD) who would receive six sessions of systematic desensitization without music, in addition to their standard treatment. At the end of the draw process, the placement of each individual in one of the aforementioned groups was publicly 
announced to all participants of the study. Until the second session of the study, 4 participants of MASD group and 5 participants of SD group retired from the study either due to leaving the organization where they had been receiving treatment or due to interrupting their participation in the study. These participants requested their data to be withdrawn from the study although it was clarified in the consent form that these would be anonymized. In total, 12 individuals diagnosed with alcohol use disorders and 9 individuals diagnosed with drug use disorders followed the study to its completion. It must be noted that when designing the study, the researchers intended to include a control group. However, the preparatory phase of the trial prior to the information groups revealed a high risk of ending up with groups with a problematic low number of participants. As a result, the study design was finalized as described above.

All participants participated in an individual interview during which they described in detail three situations of everyday life that they experienced as high-risk for relapse due to the presence of substance-conditioned cues. The situations were chosen based on the criteria of frequency and craving intensity. Subsequently, hierarchies for gradual exposure to each situation were collaboratively built by the researchers and the participants. The process which would be followed in each session was fully explained to each participant. A written guide explaining all steps of the process was also given to them, so that participants were fully aware of the process to which they assented. Participants were also informed that further guidance and support could be provided during the therapeutic sessions.

The baseline evaluation was composed of a socio-demographic questionnaire, three self-report questionnaires and a craving assessment during exposure to external substanceconditioned cues. The latter involved a fifteen-minute film projection that included the most salient substance-conditioned cues as identified by participants during the individual interviews, namely substance paraphernalia, substance use and substance dealing. 
Participants assigned to the MASD group were then presented with the same music selection that had been used in our previous study which investigated the therapeutic effects of music-assisted systematic desensitization (Stamou et al., 2016), namely the "Pure spirit of relaxation" selection composed by Hot Yoga Masters which consists of 3 musical pieces of New Age relaxing music entitled "Calming eastern temple of clarity" (Hot Yoga Masters, 2013/2012, track 1), "Enchanted garden of peace" (Hot Yoga Masters, 2013/2012, track 2) and "Soothing sea of tranquillity" (Hot Yoga Masters, 2013/2012, track 3). Each piece had an approximate duration of 40 minutes $( \pm 1$ minute). All three musical pieces shared similar musical characteristics, namely very slow and stable tempo (40-50bpm), soft dynamics, low level of volume, consistent textural combination of gentle sounds (mainly ambient sounds performed in synthesizers and sounds of nature, such as running water and forest sounds) and instruments (flute, guitar or piano), legato melodies in steady key signatures, simple chord sequences, and the absence of lyrics and accented rhythmic patterns. These musical features are very often found in New Age music and are common elements of what is currently considered as relaxing or sedative music (Radocy \& Boyle, 2003). The music selection process took place in a quiet room where MASD participants listened all together to a fifteen-minute sample of each piece and were asked to discuss how the music made them feel in terms of valence, i.e. pleasant vs unpleasant, and arousal, i.e. relaxing vs energizing, as well as if they had listened to those or similar musical pieces during substance use. All participants reported at least one of the musical pieces as pleasant and relaxing and highlighted that this kind of music did not match at all their music preferences and habits when they were using substances. They were, then, asked to choose among the pieces they found relaxing the ones they preferred to use during the phase of treatment. Out of the 11 MASD participants, 5 selected the "Calming eastern temple of clarity", 4 the "Soothing sea of tranquillity" and 2 the "Enchanted garden of peace". 


\subsubsection{Treatment phase}

MASD and SD participants received two therapeutic sessions per week, for a total period of three weeks. All sessions were group-based and were conducted in isolated quiet rooms with no external noises, within the organizations where the study took place. The equipment used for the MASD sessions was composed of individual Turbo-X MP3 devices with Turbo-X regular not noise-cancelling earbuds. The maximum decibel setting for the MP3 devices was 68 decibels and participants could adjust the volume of the music according to their preferences. All sessions were conducted by the first author who is a researcher $(\mathrm{PhD}$ in Psychology) trained in systematic desensitization but not a practising clinician. The researchers did not know any of the participants before the beginning of this study and were not involved in any aspect of the treatments provided by the organizations where the study took place. Therefore, there was no dual clinician-researcher role bias involved in the study.

MASD sessions began with a brief explanation by the researchers on the therapeutic course of the session to each participant and a reminder of the process that must be followed during imaginary exposure as discussed and explained during the individual interviews. During this interval participants could also ask for clarifications. Subsequently, participants listened for twenty minutes to the New Age music selection they had chosen in the pretreatment phase, in order to relax. Following, they rated the intensity of their craving, anxiety and tension on a scale from 0 to 100 and commenced the imaginary exposure to the high-risk situation which lasted for 50 minutes, following the hierarchy-steps written guide that was created after the individual interviews and which was given to participants in the form of a paper file, as well as the instructions given to them by the researchers. During imaginary exposure, participants continued to listen in the individual MP3 devices to the New Age

music selection they had chosen, so that counterconditioning of the high risk situation would 
be facilitated and the psychophysiological responses associated with the accompanying craving would be modified. Every 10 minutes participants were asked to evaluate the intensity of their craving in a scale from 0 to 100 . Each session ended with a ten-minute feedback during which participants discussed their experience with the researchers.

SD sessions began with a brief introduction by the researchers in order to explain the session course to each participant, remind them of the process that must be followed during imaginary exposure as discussed and explained during the individual interviews, and answer to potential questions. Subsequently, SD participants rated the intensity of their craving, anxiety and tension on a scale from 0 to 100 and began the process of imaginary exposure to the high-risk situation which lasted for 50 minutes, following the gradual steps of the corresponding written hierarchy that was built during the individual interviews and which was given to participants in the form of a paper file, as well as the instructions offered by the researchers. During exposure, participants were asked to evaluate their craving intensity every 10 minutes on a scale from 0 to 100 . Each session concluded with a brief feedback where participants could discuss their experience with the researchers.

In case of persisting craving urges after the end of the sessions of both groups, the researchers and members of each organization where the study took place stayed with the participants until the urges completely faded out in order to eliminate any possibility for relapse.

\subsubsection{Post-treatment phase}

The baseline measurements were repeated immediately after the end of the treatment phase and at a follow-up visit which took place one month later. Participants were aware of their right to obtain, upon request, their personalized data resulting from these measurements, after all evaluations were over. 


\subsection{Outcome Assessments}

The baseline and post-treatment assessments were conducted using the following instruments:

\section{i) Symptoms Checklist-90-R Derogatis (SCL-90-R)}

Symptoms Checklist 90 (Derogatis, 1993) is an instrument that measures ten categories of psychopathological symptoms, including depression. Although these are rather regarded as symptom dimensions and do not directly correspond to a diagnosis based on DSM-V, the SCL-90 is considered to be one of the most reliable instruments for assessing a treatment effect on the depression symptoms of individuals with SUD (Deady, 2009). The SCL-90 is normed on adult psychiatric outpatients and inpatients, as well as on adolescent non-patients. The internal consistency reliability of the instrument in measuring depression (Cronbach's alpha) has been estimated at 0.9 (Horowitz, Rosenberg, Baer, Ureno, \& Villasenor, 1988).

\section{ii) Craving Beliefs Questionnaire (CBQ)}

The Craving Beliefs Questionnaire (Wright, 1993) is a commonly employed instrument during CBT interventions for substance addiction treatment (Romo \& Graziani, 2015). CBQ assesses the existence of maladaptive beliefs on craving that negatively influence perceived control over substance use and increase the possibility for relapse. It consists of 20 items, such as "I have no control over my craving urges" and "I will experience craving for the rest of my life" that are rated in a 6 point Likert-type scale. The CBQ has been further validated with heroin addicted individuals and the factorial analysis revealed three factors, i.e. negative coping, compulsive behaviour and will power, accounting for $54.6 \%$ of the variance (Chang et al., 2011). The CBQ has strong internal consistency reliability in measuring the three factors as the related Cronbach alphas range from .81 to .92 (Chang et 
al., 2011). This instrument was used in order to investigate the capacity of the two treatments to reduce substance-related craving beliefs that promote substance use and relapse.

\section{iii) Craving Reactivity Scale (CRS)}

The Craving Reactivity Scale is a modification of the Emotion Reactivity Scale (Nock, Wedig, Holmberg, \& Hooley, 2008) made by the researchers of this study, so that the instrument would exclusively focus on the emotion of craving. The CRS assesses craving reactivity in everyday life via 15 questions, such as "I tend to experience strong craving very easily" and "When I feel craving, it is the only thing I can think for a long time", that are rated in a Likert-type scale as follows: $0=$ Not at all like me, $1=\mathrm{A}$ little like me, $2=$ Somewhat like me, 3=A lot like me, 4=Completely like me. The original scale had been normed on young adults and adolescents and shows strong internal consistency $(\alpha=.94)$, and convergent, divergent and criterion-related validity. In the context of this study, the CRS was used in order to examine the effect of MASD and SD on everyday life craving reactivity since low capacity to cope with craving is highly related with relapse (Heinz, Beck, Grüsser, Grace, \& Wrase, 2009).

\section{iv) Film projection measurements}

The primary objective of this study was to compare the capacity of MASD and SD interventions to reduce craving responses during exposure to external substance-conditioned cues. For this reason, participants watched in two different groups a fifteen-minute film that involved substance-conditioned cues related with their substance of addiction. The films were chosen by the researchers based on findings produced from the individual interviews in the pre-treatment period. They mainly included cues, such as substance paraphernalia and substance use and dealing, which were reported by participants as strongly conditioned with substance use and capable of provoking a relapse. All films involved these cues in similar frequency and context. 
Before the craving measurements took place, researchers fully explained all related issues to the participants so as to maximize the accuracy and validity of their responses (Moeller, Konova, \& Goldstein, 2015). More specifically: (a) it was made clear to participants that by "craving", they would all mean the intense desire to consume the substance of addiction, (b) participants were encouraged to honestly report the intensity of their craving, and (c) participants were asked not to put any effort in being defensive or insensitive to the content of the films. Concerning the latter, it was explained to participants that such effort would result in inaccurate craving reports and therefore would not allow reliably tracking their therapeutic progress.

During the film projections, the sound was muted so as to prevent the music from affecting participants or distracting their attention. Each film was paused every five minutes and participants were asked to rate the intensity of their craving on a scale from 0 to 100 . This scale derived from the Subjective Units of Distress Scale developed by Wolpe (1969) that measured the levels of distress from 0 to 100 , in the form of a "distress thermometer". The scale was modified to a "craving thermometer" for rating craving intensity, ranging from $0=\mathrm{I}$ feel totally relaxed to $100=$ The highest degree of craving I have ever felt. Participants also provided craving rates immediately before and after the film projections. In case of persisting craving urges after the film projections, the researchers and members of each organization where the study took place stayed with the participants until the urges completely faded out so as to eliminate any possibility for relapse.

In order to avoid potential learning effects, participants watched a different film during the baseline and post-treatment measurements. At baseline, half of the participants of each group watched the film that the other half watched after the end of treatment and vice versa. In the follow-up assessment which took place two months after the beginning of the treatment phase, each group watched the film of the baseline evaluation. 


\section{v) Participation evaluation questionnaire}

The Participation Evaluation Questionnaire (PEQ) was developed by the researchers and aimed at getting participants' feedback on the perceived benefits or negative effects of their participation in the study. It consisted of 4 items, such as "Has your participation in this study contributed to your treatment? If yes, please describe how" " and "Would you describe your participation in this study as positive or negative? Please describe the way in which it has influenced you". All items included both a closed and an open-ended question. The PEQ was completed by all participants during the post-treatment and follow-up measurements.

\section{Results}

The age of the 17 male and 4 female substance addicted individuals that participated in the study ranged from 19 to 56 years $(M=39.84, S D=9.1)$ and their time in treatment ranged from 0.5 to 21 months $(M=4.67, S D=5.16)$ in one of the three substance rehabilitation programs (see Table 1). Results showed that $57 \%$ of the participants had not been diagnosed with any comorbid disorders while all others were mainly diagnosed with depression and anxiety disorders. In regards to prior music training, $47.6 \%$ of participants had been involved in music studies and performance for a period between 1 and 25 months $(M=$ $8, S D=9.1)$ during their lives.

Normality and outlier tests conducted at baseline did not report any significant results outside the accepted ranges in any of the dependent variables of the study. Chi-Square tests did not reveal any significant between-group frequency differences regarding age, time in treatment, gender and substance of addiction.

Pearson product-moment bivariate correlations were computed at baseline to observe potential associations between the dependent variables of the study. The results are summarized in Table 2. Analysis showed that craving intensity during exposure to external 
cues associated with substance use was positively correlated with everyday life craving reactivity $(r=0.539, p=0.012)$. This indicates that the higher the level of craving experienced during exposure to external substance-conditioned cues the more intense is everyday life craving reactivity. Analysis also revealed that craving reactivity in everyday life was positively correlated with overall craving beliefs $(r=0.469, p=0.032)$, craving beliefs associated with will power $(r=0.512, p=0.018)$ and depression symptoms $(r=$ $0.449, p=0.041)$. Hence, the more intense everyday craving reactivity is the higher are the levels of depression symptoms, overall craving beliefs and craving beliefs associated with will power. As expected, overall craving beliefs were positively correlated with craving beliefs associated with will power $(r=0.904, p<0.001)$, compulsive behaviour $(r=0.736, p$ $<0.001)$ and negative coping $(r=0.676, p=0.001)$. Similarly, craving beliefs associated with will power were positively correlated with compulsive behaviour and negative coping craving beliefs $(r=0.517, p=0.016$ and $r=0.495, p=0.023$ respectively). These findings indicate that the higher overall craving beliefs are the more intense the levels of each CBQ factor become. A similar relationship also appears to exist among the CBQ factors. Overall craving beliefs were also found to correlate with depression symptoms $(r=0.454, p=0.039)$, which indicates that the more intense the symptoms of depression are the more severe overall craving beliefs become. Additionally, craving beliefs associated with will power were positively correlated with symptoms of depression $(r=0.467, p=0.033)$. These findings imply that the higher depression symptoms are the more severe will power craving beliefs become.

\subsection{Treatment outcomes}

We hypothesized that New Age relaxing music not formerly associated with substance use, combined with systematic desensitization would be more effective than systematic desensitization without music in reducing craving responses to external substance- 
conditioned cues, which comprised the primary outcome of the study. We further aimed at investigating potential differences between the therapeutic effects induced by New Age relaxing music combined with systematic desensitization and the effects elicited by systematic desensitization without music, on craving beliefs (overall craving beliefs, craving beliefs associated with compulsive behaviour, craving beliefs related with negative coping and craving beliefs linked with will power), craving reactivity in everyday life and symptoms of depression, which were the secondary outcomes of the study. A mixed-design $2 \times 3$ ANOVA with Tukey's post-hoc tests was conducted in order to investigate the within- and between-subjects effects in the dependent variables of the study, as well as the interaction between time and group across the three time points of the study $(\mathrm{T} 1=$ pre-treatment, $\mathrm{T} 2=$ post-treatment and $\mathrm{T} 3=$ follow-up). Although not necessary for the interpretation of the findings, ancillary independent t-tests were also conducted in order to compare the means of each group in the variables of craving, tension and anxiety that were measured before the beginning of imaginary exposure in each session, to observe if MASD and SD participants began imaginary exposure with different levels of craving, tension or anxiety.

Results of craving responses to cues conditioned with substance use showed that there was a significant difference across the three time points, $F(2,38)=9.98, p<0.001, \eta_{p}^{2}=$ 0.34. Between-group comparisons revealed that MASD participants presented significantly lower scores than SD (see Table 3) at T2 $(p=0.03)$, but no overall significant differences between groups were found, $F(1,19)=0.33, p=0.58, \eta_{p}{ }^{2}=0.017$. However, a significant interaction between time and group was observed, $F(2,38)=6.64, p=0.003, \eta_{p}{ }^{2}=0.26$ (see Figure 2a). Following up this interaction indicated that there was no significant difference between groups at baseline and that MASD group presented a significant decrease from $\mathrm{T} 1$ to $\mathrm{T} 2$ and from $\mathrm{T} 1$ to $\mathrm{T} 3$, as opposed to the SD group that exhibited decreases from T2 to T3 and from T1 to T3 which, however, were not statistically significant (see Figure 3a). These 
findings indicate that music-assisted cue counterconditioning may be more effective than unreinforced exposure in reducing craving responses to substance-conditioned cues.

The results in overall craving beliefs showed significant differences across the three time points of the study, $F(2,38)=32.26, p<0.001, \eta_{p}{ }^{2}=0.63$. No statistically significant overall differences were observed between groups, $F(1,19)=2.53, p=0.13, \eta_{p}{ }^{2}=0.11$, but MASD scores were significantly lower than SD scores (see Table 3$)$ at T3 $(p=0.049)$. No significant interaction between time and group was found, $F(2,38)=1.66, p=0.21, \eta_{p}^{2}=$ 0.08 (see Figure 2b). Post-hoc comparisons did not reveal any significant differences between groups at baseline. Significant decreases were observed within both MASD and SD groups from $\mathrm{T} 1$ to $\mathrm{T} 2$ and from $\mathrm{T} 1$ to $\mathrm{T} 3$ (see Figure $3 \mathrm{~b}$ ). These results imply that music-assisted systematic desensitization and systematic desensitization without music may induce a similar effect on overall craving beliefs, with MASD appearing to elicit a slightly more pronounced effect.

In regard to the CBQ factors, significant differences were observed across the three time points of the study in craving beliefs associated with will power, $F(2,38)=25.25, p<$ $0.001, \eta_{p}{ }^{2}=0.57$. No statistically significant overall differences were found between groups, $F(1,19)=2.73, p=0.12, \eta_{p}{ }^{2}=0.12$, but MASD participants exhibited lower scores than SD participants at T3 (see Table 3) that approached statistical significance $(p=0.055)$. Analysis did not reveal a significant interaction between time and group, $F(2,38)=1.15, p=0.33, \eta_{p}^{2}$ $=0.057$ (see Figure 2c). Post-hoc comparisons did not reveal any significant differences between groups at baseline. Significant decreases were observed within both MASD and SD groups from $\mathrm{T} 1$ to $\mathrm{T} 2$ and from $\mathrm{T} 1$ to $\mathrm{T} 3$ (see Figure $3 \mathrm{c}$ ). These findings suggest that musicassisted systematic desensitization and systematic desensitization without music elicit a 
similar positive effect on craving beliefs associated with willpower, with MASD appearing to induce a slightly more intense effect.

The results of craving beliefs related with compulsive behaviour showed significant differences across the three time points of the study, $F(2,38)=7.51, p=0.002, \eta_{p}{ }^{2}=0.28$. Although MASD participants presented significantly lowers scores than SD participants (see Table 3) at T3 $(p=0.039)$, no statistically significant overall differences were observed between groups, $F(1,19)=1.86, p=0.19, \eta_{p}{ }^{2}=0.09$. However, a significant interaction between time and group was found, $F(2,38)=3.09, p=0.049, \eta_{p}{ }^{2}=0.14$ (see Figure $2 \mathrm{~d}$ ). More specifically, data showed no significant difference between groups at baseline and a significant decrease from $\mathrm{T} 2$ to $\mathrm{T} 3$ and from $\mathrm{T} 1$ to $\mathrm{T} 3$ within the MASD group, as opposed to the SD group that did not exhibit any significant changes (see Figure $3 \mathrm{~d}$ ). These results indicate that only music-assisted systematic desensitization may elicit positive changes on craving beliefs related with compulsive behaviour but not to an extent that would make them statistically significant compared to the effects of systematic desensitization without music.

Findings on craving beliefs associated with negative coping revealed significant differences across the three time points of the study, $F(2,38)=13.01, p<0.001, \eta_{p}{ }^{2}=0.4$. No statistically significant differences between groups, $F(1,19)=1.58, p=0.23, \eta_{p}{ }^{2}=0.07$, or interaction between time and group, $F(2,38)=0.06, p=0.95, \eta_{p}^{2}=0.003$, were found (see Figure 2e). Post-hoc comparisons did not reveal any significant differences between groups at baseline. Significant decreases were observed within both MASD and SD groups from $\mathrm{T} 1$ to $\mathrm{T} 2$ and from $\mathrm{T} 1$ to $\mathrm{T} 3$ (see Figure 3e). These findings suggest that music-assisted systematic desensitization and systematic desensitization without music may induce a similar effect on craving beliefs related with negative coping. 
The analysis of the results on craving reactivity in everyday life revealed that there was a significant difference across the three time points of the study, $F(2,38)=30.88, p<$ $0.001, \eta_{p}{ }^{2}=0.62$, but no significant differences between groups, $F(1,19)=0.08, p=0.79$, $\eta_{p}{ }^{2}=0.004$, nor a significant interaction between time and group, $F(2,38)=0.03, p=0.95$, $\eta_{p}{ }^{2}=0.001$ (see Figure 2f). Post-hoc comparisons did not show any significant differences between groups at baseline and revealed significant decreases within both MASD and SD groups from $\mathrm{T} 1$ to $\mathrm{T} 2$ and from $\mathrm{T} 1$ to $\mathrm{T} 3$ (see Figure $3 \mathrm{f}$ ). These results imply that musicassisted systematic desensitization and systematic desensitization without music may be similarly effective in reducing craving reactivity in everyday life.

In terms of depression symptoms, the results showed that there were statistically significant changes across time, $F(2,38)=20.79, p<0.001, \eta_{p}{ }^{2}=0.52$, but no significant differences between groups, $F(1,19)=0.07, p=0.8, \eta_{p}{ }^{2}=0.003$, nor a significant interaction between time and group, $F(2,38)=0.36, p=0.71, \eta_{p}{ }^{2}=0.02$ (see Figure $2 \mathrm{~g}$ ). Post-hoc comparisons revealed that there were no significant differences between groups at baseline. Significant decreases were observed within MASD group from T2 to T3 and from $\mathrm{T} 1$ to $\mathrm{T} 3$, as well as within SD group from $\mathrm{T} 1$ to $\mathrm{T} 2$ and from $\mathrm{T} 1$ to $\mathrm{T} 3$ (see Figure $3 \mathrm{~g}$ ). These findings indicate that music-assisted systematic desensitization and systematic desensitization without music may positively influence depression symptoms at a similar level.

The results of craving, tension and anxiety measurements that took place immediately before the beginning of imaginary exposure in each therapeutic session, did not reveal statistically significant differences between MASD and SD in any of the sessions. These results show that during the sessions MASD and SD participants commenced the imaginary 
exposure with levels of craving, tension and anxiety that did not significantly differ between them.

As $43 \%$ of the study population were diagnosed with comorbid disorders - mainly depression - ancillary analysis was conducted in order to determine if there were differences between the changes experienced by participants with and participants without comorbid conditions. Baseline comparisons did not reveal any statistically significant differences between these two groups. Analysis of variance also showed that MASD and SD therapeutic effects did not significantly differ between participants with and participants without comorbid disorders, except for the variable of craving beliefs. More precisely, amelioration of overall craving beliefs and craving beliefs associated with will power was statistically significantly higher for participants with comorbid disorders from T1 to T2 $(p=.039$ and $p=$ .027 respectively). Changes that approached statistical significance were also observed for the same participants in the variables of overall craving beliefs and craving beliefs linked with negative coping from T1 to T3 ( $p=.062$ and $p=.066$ respectively). These findings imply that changes induced by MASD and SD on overall craving beliefs and on craving beliefs associated with will power and negative coping may be influenced by factors associated with comorbid conditions.

Despite the fact that investigating potential differences in the effectiveness of the two treatment forms according to duration of treatment, substance of addiction or prior music experiences was not among our research questions, ancillary analyses were conducted for this purpose. Baseline independent t-tests and ANOVA between-group comparisons were conducted in order to compare baseline means and the effectiveness of MASD and SD according to duration of treatment. For this analysis, participants were divided in two groups, namely those who received treatment for longer and those who received treatment for less 
than 4.67 months, which was the average duration of treatment in the study sample. Both analyses did not reveal any statistically significant differences between groups. The same ancillary tests were conducted in order to investigate potential differences according to substance of addiction (alcohol vs. drugs) and prior music experiences (music training, member of a music band, music studies), None of the analyses revealed any statistically significant results. These results suggest that the effectiveness of MASD and SD as additive therapeutic modalities do not differ in relation to duration of treatment and substance of addiction, and are not influenced by prior music experiences. An ancillary ANOVA betweengroup comparison was also conducted to examine potential differences within MASD according to the music selected by the participants. The analysis did not produce any statistically significant results for any of the dependent variables, which implies that all musical pieces or combinations thereof assisted systematic desensitization in a similar manner.

We also investigated the possibility that changes in the dependent variables were affected by the amount of hours spent weekly in music activities by participants during the study. Interestingly, 18 of the 21 participants engaged to at least one music activity for a minimum duration of one hour per week, with music listening being the most frequent activity (1-2 hours per week for 10 MASD and 8 SD participants) followed by playing musical instruments (1-2 hours per week for 2 MASD participants who also listened to music for 1-2 hours weekly). Ancillary Pearson product-moment bivariate correlation analysis did not reveal any statistically significant results and showed that external music activities during the study were not associated with MASD and SD therapeutic effects.

Data provided through the PEQ showed that $90.5 \%$ of the participants considered their participation in the study as positive, whereas $9.5 \%$ reported their experience as neither positive nor negative. From the participants who considered their participation as 
therapeutically beneficial, $42.9 \%$ reported enhanced coping skills for high-risk situations as the main therapeutic benefit, $33.3 \%$ highlighted an elevated capacity to experience and face the emotions of fear and craving in everyday life, while $23.8 \%$ referred to the increased control over craving urges and emotions during exposure to cues and situations conditioned with substance use. Importantly, session attendance rate was high during the study $(M=5.15$, $S D=.79)$ among participants who followed the study to its completion, which indicates that participants were willing to engage in a challenging treatment form. Pearson product-moment bivariate correlation analysis was conducted to investigate potential associations between session attendance and treatment effects on the dependent variables of the study but did not show any statistically significant results.

\section{Discussion}

In the present study, we hypothesized that listening to New Age relaxing music not formerly associated with substance use, combined with systematic desensitization can reduce craving responses to external substance-conditioned cues significantly more that systematic desensitization without music. The main objective of the study was to investigate if musicassisted cue exposure focused on counterconditioning can be more effective than unreinforced exposure without music in reducing craving responses to substance-conditioned cues, which was the primary outcome of the study, and to examine the potential contribution of New Age music in the therapeutic process. The secondary objectives of the study were to investigate if music-assisted counterconditioning of substance-related cues can induce more distinct changes than unreinforced exposure via systematic desensitization without music on: a) craving reactivity in everyday life, b) craving beliefs (overall craving beliefs, craving beliefs associated with compulsive behaviour, craving beliefs related with negative coping 
and craving beliefs linked with will power), and c) symptoms of depression, which were the secondary outcomes of the study.

The results of the study revealed statistically significant amelioration of craving responses to substance-conditioned cues within MASD, an effect that appeared to continue one month after the end of treatment, as opposed to SD that did not present any statistically significant improvement. However, no statistically significant overall differences were found between groups. Considering the trend of the observed effects, the relatively short period of the intervention and the fact that the two groups significantly differed between them at T2 (see Table 3), it is possible that significant differences could have been found between MASD and SD if the intervention period had been longer. The fact that the two groups did not significantly differ between them in levels of craving, anxiety and tension before the beginning of imaginary exposure in each treatment session also seems to argue in favour of this argument as it indicates that music-assisted counterconditioning may induce better effects than unreinforced exposure without music across time. This notion seems to be consistent with prior findings which propose cue counterconditioning as a more efficient modality than plain unreinforced exposure for reducing craving responses to substanceconditioned cues (Stamou et al., 2016; Van Gucht et al., 2010). If future studies verify this claim, music-assisted cue exposure interventions could prove to be useful additive treatment modalities for facilitating positive behavioural changes and preventing relapse during substance addiction treatment.

Craving reactivity in everyday life was found to be significantly improved within both MASD and SD groups, with MASD presenting a slightly more pronounced effect. It appears that the amelioration of cue-induced craving responsivity has facilitated this change since the improvement of craving responses to substance-conditioned cues was mediated by a threeweek therapy that focused on counterconditioning cues that posed a high risk for relapse in 
participants' everyday lives. Baseline correlations support this notion as craving intensity during exposure to external cues associated with substance use was positively correlated with everyday life craving reactivity. Although only MASD participants displayed significant reductions in craving responses to substance-conditioned cues, the decreases within SD group in this variable combined with the elevated capacity to face fear during exposure to substance-related cues that was reported by SD participants, may have contributed to the amelioration of everyday craving reactivity within $\mathrm{SD}$, to an extent that did not allow for statistically significant changes to be observed between the groups. It would be interesting to investigate if such between-group differences could be found after longer periods of treatment. These findings, although deriving from a study with a relatively small sample size, are indicative of the importance of cue-exposure therapy in substance addiction treatment and support prior similar views which have highlighted the important role of cue-induced craving in relapse (Fox, Bergquist, Hong, \& Sinha, 2007; Manley, 2008). If future studies reveal a potentially significant role of the duration of the intervention, MASD may prove to be a useful complementary technique for sustaining abstinence and allowing more complicated therapeutic targets to be addressed under less pressure in everyday life.

The reduction of craving in response to substance-conditioned cues and the improvement of craving reactivity in everyday life appear to be of critical importance as they seem to have mediated the amelioration of other secondary outcomes of the study. In support of this view, baseline correlations in our study showed that everyday craving reactivity was positively correlated with depression symptoms. As already discussed, everyday craving reactivity was improved within both MASD and SD in a similar manner. This change seems to have induced positive alterations in depression symptoms of both groups. The MASD group exhibited a slightly more pronounced within-group effect, potentially due to the more distinct changes in craving responses to substance-conditioned cues (see Figure 4). If these 
findings are verified by future studies, MASD may be capable of contributing to relapse prevention by altering depression symptoms via the modification of cue reactivity and the amelioration of craving reactivity in everyday life, while SD via the latter. This is in agreement with studies which have shown that psychopathological symptoms, such as depression, are highly associated with craving and substance use (Brady \& Verduin, 2005; Pierucci-Lagha et al., 2004; Wedekind et al., 2010) and that high reactivity to substanceassociated cues elicits increases in depression which decrease after cue-exposure interventions (Franken, de Haan, van der Meer, Haffmans, \& Hendriks, 1999).

As craving has been highly associated with craving beliefs (Chang et al., 2011), changes in this variable were expected to be observed that would be related to positive alterations of craving responses to substance-conditioned cues and to the modification of everyday craving reactivity (see Figure 4). These expectations were supported by the positive baseline correlation between everyday craving reactivity and overall craving beliefs. Indeed, the results showed that overall craving beliefs' amelioration followed a similar pattern with improvement of craving reactivity in everyday life within both MASD and SD groups. Although no statistically significant differences were found between groups overall, MASD participants presented a slightly more pronounced effect and their scores were significantly lower than SD at T3 (see Table 3), indicating the already established link between cue reactivity and the development of craving beliefs (Beck, Wright, Newman, \& Liese, 1993).

A similar effect was also observed for craving beliefs associated with will power, with differences between MASD and SD approaching statistical significance at T3 (see Table 3), but not for craving beliefs linked with negative coping. These findings seem to imply that positive changes in cue reactivity could potentially modify overall craving beliefs and the perceived will power to cope with craving but this effect does not seem to transfer to the perceived capacity to cope with other situations that may include negative stimuli difficult to 
deal with. This finding seems reasonable as MASD aimed at counterconditioning only specific situations that involved substance-conditioned cues and not at improving reactivity to other high-risk situations that involved cues not counter-conditioned during the study. It would be interesting to investigate, however, if longer periods of intervention could result in statistically significant differences between MASD and SD in overall craving beliefs and in craving beliefs related with will power.

Of note, statistically significant differences were found in craving beliefs linked with compulsive behaviour, in which significant effects were observed only within MASD. Although the two groups did not significantly differ between them overall, MASD scores were statistically significantly lower than SD at T3 (see Table 3), indicating that longer periods of intervention could potentially lead to more pronounced differences between MASD and SD. It is possible that the counterconditioning of cues associated with substance use and the significant modification of the implicated craving responses induced a positive effect in craving beliefs linked with compulsive behaviour, as MASD participants realized that behavioural responses to stimuli once considered as impossible to resist could be modified with success. Consistent with this, compulsive behaviour has been highly associated with craving (Lubman, Yucel, \& Pantelis, 2004) and high cue-reactivity (Volkow, 2010; Volkow \& Morales, 2015; Volkow, Wang, Fowler, Tomasi, \& Telang, 2011), and is considered as one of the most fundamental features of addictive behaviours (Dalley, Everitt, \& Robbins, 2011; Koob \& Volkow, 2010). The impact of MASD on compulsive behaviour craving beliefs may have also been facilitated by the effect of music listening on brain mechanisms associated with compulsivity. More precisely, compulsive behaviour in individuals with SUD has been linked with low density of dopamine receptors in the nucleus accumbens of the brain (NAc) which, in turn, has been found to be related with the disrupted function of brain regions associated with compulsivity, biased decision-making and 
substance-seeking behaviours (Volkow et al., 2011). Of note, pleasant music has been shown to positively modulate dopamine secretion in the NAc highlighting a potential underestimated role of music in the regulation of the dopaminergic system (Blum et al., 2010). It is, thus, possible that the MASD effect on compulsive behaviour craving beliefs may have been mediated by the modulation of both bio-neurological and behavioural functions. This hypothesis remains to be investigated by future research studies.

In regard to the differences observed in craving beliefs changes between participants with and participants without comorbid disorders, they seem to be partly explained by the related pharmacological treatments. According to the therapeutic teams of the three organizations where the study took place, participants with comorbid disorders were mainly receiving anxiolytics and antidepressants. Our baseline correlations showed that depression symptoms were positively correlated with overall craving beliefs and with craving beliefs associated with will power. Furthermore, will power craving beliefs were positively correlated with craving beliefs associated with negative coping. It is, thus, possible that pharmacological treatments may have synergistically with MASD and SD facilitated the amelioration of the aforementioned craving beliefs via changes on the depression symptoms of participants.

We considered the possibility that music could elicit an attention distraction effect during systematic desensitization and provide misleading results about the capacity of MASD to counter-condition substance-related cues. Although music has been shown to be capable of inducing such an effect (Dibben \& Williamson, 2007), this was not the case in this study since the craving rates of participants were continuously monitored during the therapeutic sessions and showed that craving levels were high until the counterconditioning of high-risk situations and of the related substance-conditioned cues. Furthermore, the sound was muted during the film projections, so as not to affect participants in any way during the craving 
assessments in response to substance-conditioned cues and subsequently influence the validity of the results of the related measurements. This implies that music did not induce attention distraction during this study, but may have rather acted as an assisting agent for the counterconditioning of substance-conditioned cues.

The above claim seems to be further supported by participants' feedback. Of importance, the majority of participants rated their participation in the study as therapeutically beneficial. MASD participants mainly highlighted the benefits of enhanced coping skills and perceived self-efficacy in high-risk situations and increased control over craving urges and emotions when exposed to substance-conditioned cues. Additionally, both MASD and SD participants referred to the benefit of the elevated capacity to experience and control fear and craving in everyday life. Thus, it is possible that MASD may prove to be useful in addressing different therapeutic targets that may promote abstinence and prevent relapse. Consistent with this view, prior studies have shown that high cue reactivity is a significant risk factor for relapse (Fox et al., 2007), low coping skills and reduced selfefficacy are highly linked with substance-related expectancies and loss of control over addictive behaviours (Romo \& Graziani, 2015), while intense fear is associated with low emotion regulation skills and substance-seeking behaviours (Stathopoulou, 2010).

\subsection{Implications for clinical practice}

The findings of this study indicate that cue-exposure therapeutic interventions may be useful for substance addiction treatment, particularly when they focus on cue counterconditioning instead of unreinforced exposure. Cue counterconditioning could be the answer to past contradictory findings on cue-exposure interventions that have made clinicians hesitant to consider their wide use for addiction treatment. These interventions focused on unreinforced exposure and this could have been their fundamental flaw. Whereas cue counterconditioning proposes modifying the behavioural responses to substance-conditioned 
cues by counteracting the conditioned effects of the cue and creating a new association that facilitates abstinence, unreinforced exposure simply aims at weakening the association between the cue and the conditioned substance-seeking response, which can quite easily be reinstated and lead to relapse (Shaham, Shalev, Lu, De Wit, \& Stewart, 2003). New Age relaxing music could potentially prove to be a useful assisting agent in the counterconditioning of substance-related cues, as indicated by the related MASD decreases in craving responses to substance-conditioned cues and in craving beliefs linked with compulsive behaviour. The wide range of music genres and their potential capacity to induce positive effects on bio-psychophysiological functions according to individual and contextual characteristics, and the high preference of most individuals for specific musical pieces may prove to be important therapeutic tools to be considered by clinicians in future music-assisted cue-exposure interventions that could be tailored to the musical preferences and therapeutic needs of the substance addicted individuals, as long as the music is not associated with substance use. These interventions could potentially be capable of addressing different therapeutic targets, such as counterconditioning substance-conditioned cues, promoting transitions to problem-based coping styles, enhancing self-confidence and self-efficacy, facilitating emotion regulation, enhancing engagement to treatment, and sustaining abstinence during different stages of substance addiction treatment.

\subsection{Limitations}

There are certain limitations in the present study that need to be addressed. The small sample size limits the external validity and does not allow the generalization of our findings. Larger scales trials are needed to verify the findings and further investigate the effectiveness of music-assisted systematic desensitization in drug addiction treatment, as well as the exact contribution of music in the related therapeutic effects. The study sample has also restricted our capacity to draw safe conclusions about the potential role of gender and age in the 
therapeutic process, since female participants were outnumbered by males. Finally, the lack of a control group poses another limitation to the present study as it did not allow the potential verification of the findings of our previous randomized controlled experiment (Stamou et al., 2016) which investigated the effectiveness of music-assisted cue-exposure therapy and revealed positive findings for the therapeutic potential of music-assisted systematic desensitization in substance addiction treatment.

\subsection{Suggestions for future research}

The findings of this study appear to argue in favour of the use of music-assisted systematic desensitization in substance addiction treatment. Larger scale randomized controlled trials are needed, however, to verify the potential superiority of music-assisted cue counterconditioning over unreinforced exposure without music and shed light on the functional basis of the reported therapeutic effects and on the exact contribution of music. Studies with longer periods of intervention and real-time electronic ambulatory monitoring of everyday craving responses to substance-conditioned cues during the treatment and follow-up periods could elucidate the MASD therapeutic effects and how these would differ from cueexposure interventions that focus on unreinforced exposure. Trials could further benefit from longer follow-up periods to investigate the long-term effect of the treatment on cue reactivity and examine the potential reinstatement of cues. Studies that would include bio-physiological measurements, such fMRI scans or cortisol measurements, could also shed light on the bioneurological mechanisms involved in behaviour modification during cue-exposure interventions and depict more clearly the therapeutic contribution of music during the counterconditioning process. Additionally, trials could investigate potential differences between the therapeutic contribution of participant-selected relaxing music and that of relaxing music proposed by the researchers, to investigate the potential roles of liking and familiarity with music in the counterconditioning process, as long as the music is not 
associated with substance use. Detailed assessments of individual bio-physiological responses to music could potentially lead to music-assisted cue-exposure interventions that use music tailored to the individual that receives the treatment. Based on such assessments, future studies could investigate the capacity of tailored music to assist counterconditioning substance-related cues during both in-vitro and in-vivo cue-exposure interventions. Finally, future trials should include a significant number of female participants to determine the potential role of gender and age in the therapeutic processes of music-assisted cue-exposure therapy. Further investigation on the therapeutic contribution of music in cue-exposure interventions for substance addiction treatment and on the functional basis of the reported therapeutic effects seems warranted.

\section{Conclusions}

The results of this study imply that listening to New Age relaxing music combined with systematic desensitization may be a useful complementary intervention for the treatment of substance addiction. Of note, music seems to play a significant role in the counterconditioning of cues conditioned with substance use and in reducing the implicated craving responses, irrespective of substance of addiction and stage of treatment. Taken together with the findings of our previous study (Stamou et al., 2016), music-assisted systematic desensitization seems to be a therapeutic intervention worth investigating for the treatment of individuals diagnosed with SUD. The high rate of participation in our study and the high preference of most individuals for music (Aldridge \& Fachner, 2010) imply that music-assisted interventions may be capable of sustaining or even enhancing engagement to treatment (Dingle, Gleadhill, \& Baker, 2008; Miller, 2011), which is considered as one of the main problems during therapy (Aldridge \& Fachner, 2006). Future studies are encouraged in order to further investigate the potential contribution of music-assisted cue-exposure 
interventions and open novel avenues for interdisciplinary therapeutic practices in substance addiction treatment.

\section{Funding}

The authors would like to report that this study has not been funded.

\section{Conflict of Interest}

The authors report no conflict of interest.

\section{Acknowledgements}

The authors wish to thank all participants for their willingness to take part in the study. They further wish to thank the directors and staff of the Psychotherapeutic Centre of Osny, the Clinic of Montevideo and the Therapeutic Community of Aubervilliers. Special thanks are to be addressed to Dr. Jerôme Petitdidier, Mr. Jean-Pierre Couteron, Dr. Philippe Batel, Dr. Sylvain Balester, Mr. Valere Rogissart and Mrs. Suzie Longbottom for significantly facilitating conducting this study. 


\section{References}

Aldridge, D., \& Fachner, J. (2010). Music therapy and addictions. London: Jessica Kingsley Publishers.

Aldridge, D., \& Fachner, J. (2006). Music and altered states - consciousness, transcendence, therapy and addictions. London: Jessica Kingsley Publishers.

American Psychiatric Association. (2013). Diagnostic and Statistical Manual of Mental Disorders (5th ed.). Washington, DC: American Psychiatric Publishing.

Beck, A. T., Wright, F. D., Newman, C. F., \& Liese, B. S. (1993). Cognitive therapy of substance abuse. New York and London: The Guilford Press.

Bernatzky, G., Presch, M., Anderson, M., \& Panksepp, J. (2011). Emotional foundations of music as a non-pharmacological pain management tool in modern medicine. Neuroscience and Biobehavioral Reviews, 35(9), 1989-1999. doi: 10.1016/j.neubiorev.2011.06.005

Blood, A. J., \& Zatorre, R. J. (2001). Intensely pleasurable responses to music correlate with activity in brain regions implicated in reward and emotion. Proceedings of the National Academy of Sciences of U.S.A, 98(20), 11818-11823. doi: 10.1073/pnas.191355898

Blum, K., Chen, T. J., Chen, A. L., Madigan, M., Downs, B. W., Waite, R. L., . . Gold, M. S. (2010). Do dopaminergic gene polymorphisms affect mesolimbic reward activation of music listening response? Therapeutic impact on Reward Deficiency Syndrome (RDS). Medical Hypotheses, 74(3), 513-520. doi: 10.1016/j.mehy.2009.10.008

Bradt, J., \& Dileo, C. (2009). Music for stress and anxiety reduction in coronary heart disease patients. Cochrane Database of Systematic Reviews Medical, 2. doi: 10.1002/14651858.CD006577.pub2

Brady, K. T., \& Verduin, M. L. (2005). Pharmacotherapy of comorbid mood, anxiety, and substance use disorders. Substance Use and Misuse, 40(13-14), 2021-2041, 2043-2048. doi: 10.1080/10826080500294924

Brattico, E., Alluri, V., Bogert, B., Jacobsen, T., Vartiainen, N., Nieminen, S., \& Tervaniemi, M. (2011). A functional MRI study of happy and sad emotions in music with and without lyrics. Frontiers in Psychology, 2, 308. doi: 10.3389/fpsyg.2011.00308

Chanda, M. L., \& Levitin, D. J. (2013). The neurochemistry of music. Trends in Cognitive Sciences, 17(4), 179-193. doi: 10.1016/j.tics.2013.02.007

Chang, C. W., Huang, C. W., Wu, W. H., Wang, B. E., Liu Y. L., Shen, H. C., \& Lee, T. S. H. (2011). Psychometric properties of the Chinese craving beliefs questionnaire for heroin abusers in methadone treatment. BMC Psychiatry, 11(39). doi: 10.1186/1471-244X-11-39

Dalley, J. W., Everitt, B. J., \& Robbins, T. W. (2011). Impulsivity, compulsivity, and top-down cognitive control. Neuron - Cell, 69(4), 680-694. doi:10.1016/j.neuron.2011.01.020

Deady, M. (2009). A review of screening, assessment and outcome measures for drug and alcohol settings. Retrieved from Health Well website: http://www.thehealthwell.info/node/252189

Derogatis, L. R. (1993). SCL-90-R: Administration, scoring \& procedures manual-ii for the r(evised) version and other instruments of the psychopathology rating scale series. Minneapolis: National Computer Systems.

Dibben, N., \& Williamson, V. J. (2007). An exploratory survey of in-vehicle music listening. Psychology of Music, 35(4), 571-589. doi: 10.1177/0305735607079725

Dingle, G. A., Gleadhill, L., \& Baker, F. A. (2008). Can music therapy engage patients in group cognitive behaviour therapy for substance abuse treatment?. Drug and Alcohol Review, 27(2), 190-196. doi: 10.1080/09595230701829371

Fox, H. C., Bergquist, K. L., Hong, K. I., \& Sinha, R. (2007). Stress-induced and alcohol cue-induced craving in recently abstinent alcohol-dependent individuals. Alcoholism: Clinical and Experimental Research, 31(3), 395-403. doi: 10.1111/j.1530-0277.2006.00320.x

Franken, I. H., de Haan, H. A., van der Meer, C. W., Haffmans, P. M., \& Hendriks, V. M. (1999). Cue reactivity and effects of cue exposure in abstinent posttreatment drug users. Journal of Substance Abuse, 16(1), 81-85. doi:10.1016/S0740-5472(98)00004-X

Goldman, M., Szucs-Reed, R. P., Jagannathan, K., Ehrman, R. N., Wang, Z., Li, Y., ... \& Franklin, T. R. (2013). Reward-related brain response and craving correlates of marijuana cue exposure: 
A preliminary study in treatment-seeking marijuana-dependent subjects. Journal of Addiction Medicine, 7(1), 8-16. doi: 10.1097/ADM.0b013e318273863a

Hall, W., Carter, A., \& Forlini, C. (2015). The brain disease model of addiction: Is it supported by the evidence and has it delivered on its promises?. The Lancet Psychiatry, 2(1), 105-110. doi: 10.1016/S2215-0366(14)00126-6

Heinz, A., Beck, A., Grüsser, S. M., Grace, A. A., \& Wrase, J. (2009). Identifying the neural circuitry of alcohol craving and relapse vulnerability. Addiction Biology, 14(1), 108-118. doi: 10.1111/j.1369-1600.2008.00136.x

Hone-Blanchet, A., Wensing, T., \& Fecteau, S. (2014). The use of virtual reality in craving assessment and cue-exposure therapy in substance use disorders. Frontiers in Human Neuroscience, 8, 844. doi: 10.3389/fnhum.2014.00844

Horowitz, L.M., Rosenberg, S.E., Baer, B.A., Ureno, G. \& Villasenor, V.S. (1988). Inventory of interpersonal problems: Psychometric properties and clinical applications. Journal of Consulting and Clinical Psychology, 56(6), 885-892. Retrieved from http://www.apa.org/pubs/journals/ccp

Hot Yoga Masters (2013). Calming eastern temple of clarity. On Pure spirit of relaxation [MP3 file]. New York: Angelworks (2012).

Hot Yoga Masters (2013). Enchanted garden of peace. On Pure spirit of relaxation [MP3 file]. New York: Angelworks (2012).

Hot Yoga Masters (2013). Soothing sea of tranquillity. On Pure spirit of relaxation [MP3 file]. New York: Angelworks (2012).

Kanba, S. (2004). Although antidepressants and anxiolytics are frequently used together to treat depression in the acute phase, how effective is the concomitant use of these drugs?. Journal of Psychiatry and Neuroscience, 29(6), 485. Retrieved from http://jpn.ca/

Koob, G. F., \& Volkow, N. D. (2010). Neurocircuitry of addiction. Neuropsychopharmacology, 35(1), 217-238. doi: 10.1038/npp.2009.110

Labbe, E., Schmidt, N., Babin, J., \& Pharr, M. (2007). Coping with stress: The effectiveness of different types of music. Applied Psychophysiology and Biofeedback, 32(3-4), 163-168. doi: 10.1007/s10484-007-9043-9

Lee, J., Lim, Y., Graham, S. J., Kim, G., Wiederhold, B. K., Wiederhold, M. D., . . Kim, S. I. (2004). Nicotine craving and cue exposure therapy by using virtual environments. CyberPsychology and Behavior, 7(6), 705-713. doi: 10.1089/cpb.2004.7.705

Levy, N. (2013). Addiction is not a brain disease (and it matters). Frontiers in psychiatry, 4, 24. doi: 10.3389/fpsyt.2013.00024

Lubman, D. I., Yucel, M., \& Pantelis, C. (2004). Addiction, a condition of compulsive behaviour? Neuroimaging and neuropsychological evidence of inhibitory dysregulation. Addiction, 99(12), 1491-1502. doi: 10.1111/j.1360-0443.2004.00808.x

Manley, D. S. (2008). Acceptability and applicability of cue exposure therapy as a relapse prevention intervention for individuals who have substance misuse and mental health problems. Mental Health and Substance Use, 1(2), 172-184. doi:10.1080/17523280802020099

McHugh, R. K., Park, S., \& Weiss, R. D. (2014). Cue-induced craving in dependence upon prescription opioids and heroin. American Journal on Addictions, 23(5), 453-458. doi: 10.1111/j.1521-0391.2014.12129.x

Menon, V., \& Levitin, D. J. (2005). The rewards of music listening: Response and physiological connectivity of the mesolimbic system. Neuroimage, 28(1), 175-184. doi:10.1016/j.neuroimage.2005.05.053

Miller, E. (2011). Bio-Guided Music Therapy. London and Philadelphia: Jessica Kingsley Publishers.

Moeller, S. J., Konova, A. B., \& Goldstein, R. Z. (2015). Multiple ambiguities in the measurement of drug craving. Addiction, 110(2), 205-206. doi: 10.1111/add.12726

Myers, K. M., \& Carlezon, W. A. Jr. (2010). Extinction of drug- and withdrawal-paired cues in animal models: Relevance to the treatment of addiction. Neuroscience \& Biobehavioral Reviews, 35(2), 285-302. doi: 10.1016/j.neubiorev.2010.01.011

Nilsson, U. (2009). The effect of music intervention in stress response to cardiac surgery in a randomized clinical trial. Heart and Lung, 38(3), 201-207. doi: 10.1016/j.hrtlng.2008.07.008 
Nilsson, U., Unosson, M., \& Rawal, N. (2005). Stress reduction and analgesia in patients exposed to calming music postoperatively: A randomized controlled trial. European Journal of Anaesthesiology, 22(2), 96-102. doi: 10.1017/S0265021505000189

Nock, M. K., Wedig, M. M., Holmberg, E. B., \& Hooley, J. M. (2008). The emotion reactivity scale: Development, evaluation, and relation to self-injurious thoughts and behaviors. Behavior Therapy, 39(2), 107-116. doi: 10.1016/j.beth.2007.05.005

Otto, M. W., Safren, S. A., \& Pollack, M. H. (2004). Internal cue exposure and the treatment of substance use disorders: Lessons from the treatment of panic disorder. Journal of Anxiety Disorders, 18(1), 69-87. doi: 10.1016/j.janxdis.2003.07.007

Pavlov, I. P. (1927/1960). Conditional reflexes. New York: Dover Publications.

Phipps, M. A., Carroll, D. L., \& Tsiantoulas, A. (2010). Music as a therapeutic intervention on an inpatient neuroscience unit. Complementary Therapies in Clinical Practice, 16(3), 138-142. doi: 10.1016/j.ctcp.2009.12.001

Pierucci-Lagha, A., Feinn, R., Modesto-Lowe, V., Swift, R., Nellissery, M., Covault, J., \& Kranzler, H. R. (2004). Effects of rapid tryptophan depletion on mood and urge to drink in patients with co-morbid major depression and alcohol dependence. Psychopharmacology, 171(3), 340-348. doi: 10.1007/s00213-003-1588-6

Poznyak, V., Fleischmann, A., Rekve, D., Rylett, M., Rehm, J., \& Gmel, G. (2013). The World Health Organization's global monitoring system on alcohol and health. Alcohol Research: Current Reviews, 35(2), 244-249.Retrieved from http://www.arcr.niaaa.nih.gov/arcr

Radocy, R. E., \& Boyle, J. D. (2003). Psychological foundations of musical behavior (4th ed.). Springfield, IL: Charles C. Thomas.

Ramirez, J. J., Monti, P. M., \& Colwill, R. M. (2015). Brief and extended alcohol-cue-exposure effects on craving and attentional bias. Experimental and Clinical Psychopharmacology, 23(3), 159-167. doi: 10.1037/pha0000018

Romo, L., \& Graziani, P. (2015). Surmonter un problème avec l'alcool. [Getting over alcohol problems]. Paris, France: Dunod.

Sakamoto, M., Ando, H., \& Tsutou, A. (2013). Comparing the effects of different individualized music interventions for elderly individuals with severe dementia. International Psychogeriatrics, 25(5), 775-784. doi: 10.1017/S1041610212002256

Salamon, E., Kim, M., Beaulieu, J., \& Stefano, G. B. (2003). Sound therapy induced relaxation: Down regulating stress processes and pathologies. Medical Science Monitor, 9(5), 96-101. Retrieved from http://www.medscimonit.com

Salimpoor, V. N., van den Bosch, I., Kovacevic, N., McIntosh, A. R., Dagher, A., \& Zatorre, R. J. (2013). Interactions between the nucleus accumbens and auditory cortices predict music reward value. Science, 340(6129), 216-219. DOI: 10.1126/science.1231059

Salimpoor, V. N., Benovoy, M., Larcher, K., Dagher, A., \& Zatorre, R. J. (2011). Anatomically distinct dopamine release during anticipation and experience of peak emotion to music. Nature Neuroscience, 14(2), 257-262. doi:10.1038/nn.2726

Salimpoor, V. N., Benovoy, M., Longo, G., Cooperstock, J. R., \& Zatorre, R. J. (2009). The rewarding aspects of music listening are related to degree of emotional arousal. PLoS One, 4(10), 7487. doi: 10.1371/journal.pone.0007487

Sammler, D., Grigutsch, M., Fritz, T., \& Koelsch, S. (2007). Music and emotion: Electrophysiological correlates of the processing of pleasant and unpleasant music. Psychophysiology, 44(2), 293304. doi: 10.1111/j.1469-8986.2007.00497.x

Sarkamo, T., Tervaniemi, M., Laitinen, S., Forsblom, A., Soinila, S., Mikkonen, M., . . Hietanen, M. (2008). Music listening enhances cognitive recovery and mood after middle cerebral artery stroke. Brain, 131(3), 866-876. doi: 10.1093/brain/awn013

Schäfer, T., \& Sedlmeier, P. (2010). What makes us like music? Determinants of music preference. Psychology of Aesthetics, Creativity and the Arts, 4(4), 223-234. doi: 10.1037/a0018374

Shaham, Y., Shalev, U., Lu, L., De Wit, H., \& Stewart, J. (2003). The reinstatement model of drug relapse: History, methodology and major findings. Psychopharmacology, 168(1-2), 3-20. doi:10.1007/s00213-002-1224-x 
Sinha, R., Fox, H. C., Hong, K. A., Bergquist, K., Bhagwagar, Z., \& Siedlarz, K. M. (2009). Enhanced negative emotion and alcohol craving, and altered physiological responses following stress and cue exposure in alcohol dependent individuals. Neuropsychopharmacology, 34(5), 1198-1208. doi: 10.1038/npp.2008.78

Stamou, V., Chatzoudi, T., Stamou, L., Romo, L., \& Graziani, P. (2016). Music-assisted systematic desensitization for the reduction of craving in response to drug-conditioned cues: A pilot study. The Arts in Psychotherapy, 51, 36-45. doi: 10.1016/j.aip.2016.08.003

Stathopoulou, G. (2009). Gender, emotional intolerance, and mood-related cravings for substance use in treatment-seeking opiate-dependent patients (Unpublished doctoral dissertation). Boston University, Boston.

Unrod, M., Drobes, D. J., Stasiewicz, P. R., Ditre, J. W., Heckman, B., Miller, R. R., . . Brandon, T. H. (2014). Decline in cue-provoked craving during cue exposure therapy for smoking cessation. Nicotine and Tobacco Research, 16(3), 306-315. doi: 10.1093/ntr/ntt145

Van Gucht, D., Baeyens, F., Hermans, D., \& Beckers, T. (2013). The inertia of conditioned craving. Does context modulate the effect of counterconditioning?. Appetite, 65, 51-57. doi: 10.1016/j.appet.2013.01.019

Van Gucht, D., Baeyens, F., Vansteenwegen, D., Hermans, D., \& Beckers, T. (2010). Counterconditioning reduces cue-induced craving and actual cue-elicited consumption. Emotion, 10(5), 688-695. doi: 10.1037/a0019463

Volkow, N. D. (2010). Drugs, Brains and Behaviour: The Science of Addiction (Report No.14-5605). Washington: National Institute on Drug Abuse.

Volkow, N. D., Wang, G. J., Fowler, J. S., Tomasi, D., \& Telang, F. (2011). Addiction: Beyond dopamine reward circuitry. Proceedings of the National Academy of Sciences of U.S.A, 108(37), 15037-15042. doi: 10.1073/pnas.1010654108

Volkow, N. D., \& Morales, M. (2015). The brain on drugs: From reward to addiction. Cell, 162(4), 712-725. doi: 10.1016/j.cell.2015.07.046

Wedekind, D., Herchenhein, T., Kirchhainer, J., Bandelow, B., Falkai, P., Engel, K., \& HavemannReinecke, U. (2010). Serotonergic function, substance craving, and psychopathology in detoxified alcohol-addicted males undergoing tryptophan depletion. Journal of Psychiatric Research, 44(16), 1163-1169. doi: 10.1016/j.jpsychires.2010.04.002

Wolpe, J. (1969). The practice of behavior therapy. New York: Pergamon Press.

Wright, F. D. (1993). Craving beliefs questionnaire. In A. T. Beck, F. D. Wright, C. F. Newman, \& B. S. Liese, (Eds.). Cognitive Therapy of Substance Abuse (p. 312). London: The Guilford Press.

Yokoyama, A., Matsushita, S., Toyama, T., Nakayama, H., Takimura, T., Kimura, M., ... \& Yokoyama, T. (2015). Relapse prevention program consisting of coping skills training, cue exposure treatment, and letter therapy for Japanese alcoholic men who relapsed after standard cognitive-behavioral therapy. Nihon Arukoru Yakubutsu Igakkai zasshi, 50(2), 88-103. 
NEW AGE RELAXING MUSIC CAN FACILITATE CUE COUNTERCONDITIONING

Table 1. Presentation of demographic data for the two study groups.

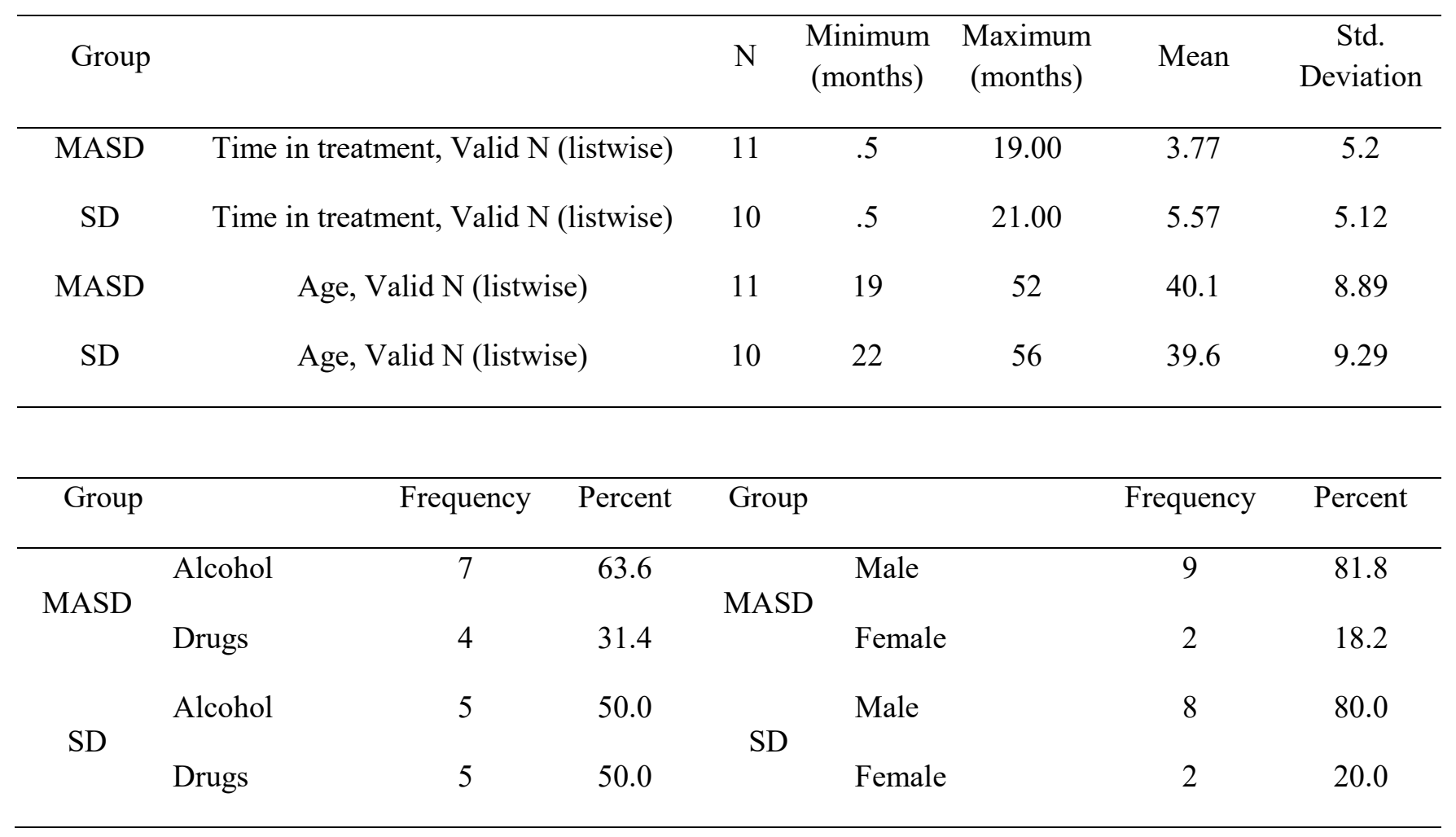


Table 2. Presentation of baseline correlations between the dependent variables of the study.

\begin{tabular}{|c|c|c|c|c|c|c|c|c|}
\hline \multicolumn{2}{|c|}{ Variable } & \multirow{4}{*}{$\begin{array}{c}\begin{array}{c}\text { Craving to } \\
\text { external } \\
\text { stimuli }\end{array} \\
1 \\
21\end{array}$} & \multirow{4}{*}{$\begin{array}{c}\begin{array}{c}\text { CBQ } \\
\text { (overall) }\end{array} \\
\\
.188 \\
.415 \\
21\end{array}$} & \multirow{4}{*}{$\begin{array}{c}\begin{array}{c}\text { CBQ } \\
\text { will } \\
\text { power }\end{array} \\
216 \\
.348 \\
21 \\
\end{array}$} & \multirow{4}{*}{$\begin{array}{c}\begin{array}{c}\text { CBQ } \\
\text { compulsive } \\
\text { behaviour }\end{array} \\
146 \\
.528 \\
21\end{array}$} & \multirow{4}{*}{$\begin{array}{c}\begin{array}{c}\text { CBQ } \\
\text { negative } \\
\text { coping }\end{array} \\
04 \\
.042 \\
21\end{array}$} & \multirow{4}{*}{$\begin{array}{c}\text { CRS } \\
.539 * \\
.012 \\
21\end{array}$} & \multirow{4}{*}{$\begin{array}{r}\begin{array}{r}\text { SCL } 90 \text { R } \\
\text { depression }\end{array} \\
304 \\
.181 \\
21\end{array}$} \\
\hline Craving to & Pearson's & & & & & & & \\
\hline external & Sig. & & & & & & & \\
\hline stimuli & $\mathrm{N}$ & & & & & & & \\
\hline \multirow{3}{*}{$\begin{array}{c}\text { CBQ } \\
\text { (overall) }\end{array}$} & \multirow{3}{*}{$\begin{array}{l}\text { Pearson's } \\
\text { Sig. } \\
\text { (2-tailed) } \\
\mathrm{N}\end{array}$} & & 1 & $.904 * *$ & $.736 * *$ & $.676^{* *}$ & $.469 *$ & $.454^{*}$ \\
\hline & & & . & .000 & .000 & .001 & .032 & .039 \\
\hline & & & 21 & 21 & 21 & 21 & 21 & 21 \\
\hline \multirow{3}{*}{$\begin{array}{l}\text { CBQ will } \\
\text { power }\end{array}$} & \multirow{3}{*}{$\begin{array}{l}\text { Pearson's } \\
\text { Sig. } \\
\text { (2-tailed) } \\
\text { N }\end{array}$} & & & 1 & $.517 *$ & $.495 *$ & $.512 *$ & $.467 *$ \\
\hline & & . & & . & .016 & .023 & .018 & .033 \\
\hline & & & & 21 & 21 & 21 & 21 & 21 \\
\hline \multirow{3}{*}{$\begin{array}{c}\text { CBQ } \\
\text { compulsive } \\
\text { behaviour }\end{array}$} & \multirow{3}{*}{$\begin{array}{l}\text { Pearson's } \\
\text { Sig. } \\
\text { (2-tailed) } \\
\text { N }\end{array}$} & & & & 1 & .291 & .328 & .256 \\
\hline & & & & & . & .201 & .146 & .262 \\
\hline & & & & & 21 & 21 & 21 & 21 \\
\hline \multirow{3}{*}{$\begin{array}{c}\text { CBQ } \\
\text { negative } \\
\text { coping }\end{array}$} & \multirow{3}{*}{$\begin{array}{l}\text { Pearson's } \\
\text { Sig. } \\
\text { (2-tailed) } \\
\mathrm{N}\end{array}$} & & & & & 1 & .283 & .235 \\
\hline & & & & & & . & .213 & .305 \\
\hline & & & & & & 21 & 21 & 21 \\
\hline \multirow{4}{*}{ CRS } & \multirow{4}{*}{$\begin{array}{l}\text { Pearson's } \\
\text { Sig. } \\
\text { (2-tailed) } \\
\text { N }\end{array}$} & & & & & & & \\
\hline & & & & & & . & 1 & $.449 *$ \\
\hline & & & & & & & is & $\begin{array}{r}.041 \\
21\end{array}$ \\
\hline & & & & & & & 21 & 21 \\
\hline \multirow{3}{*}{$\begin{array}{c}\text { SCL } 90 \text { R } \\
\text { depression }\end{array}$} & Pearson's & & & & & & & \multirow[t]{3}{*}{1} \\
\hline & Sig. & & & & & & & \\
\hline & $\begin{array}{l}\text { (2-tailed) } \\
\mathrm{N}\end{array}$ & & & & & & & \\
\hline
\end{tabular}

${ }^{*}$ Correlation is significant at 0.05 level (2-tailed)

**Correlation is significant at 0.01 level (2-tailed) 
Table 3. Presentation of all the data gathered for MASD $(n=11)$ and SD $(n=10)$ during the study $(95 \%$ confidence interval). The left column presents the results of the mixed factorial analysis of variance and the following three consecutive columns present in two levels the descriptive data of the groups compared at each time point of the study and the within-group results shown by Tukey's post-hoc tests respectively.

\begin{tabular}{l|ccc|} 
Mixed-design & T1 - MASD vs. SD & T2 - MASD vs. SD & T3 - MASD vs. SD \\
$2 \times 3$ ANOVA & $($ Mean \pm Std. Deviation, $p)$ & $($ Mean \pm Std. Deviation, $p)$ & $($ Mean \pm Std. Deviation, $p)$
\end{tabular}

\section{Film craving}

\begin{tabular}{|c|c|c|c|c|}
\hline $\begin{array}{l}\text { Within-time } \\
\text { Between-groups } \\
\text { Time x Group }\end{array}$ & $\begin{array}{c}F(2,38)=9.98 \\
p<0.001, \eta_{p}{ }^{2}=0.34 \\
F(1,19)=0.33, \\
p=0.58, \eta_{p}{ }^{2}=0.017 \\
F(2,38)=6.64 \\
p=0.003, \eta_{p}{ }^{2}=0.26\end{array}$ & $\begin{array}{c}24.32 \pm 17.12 \text { vs } 16.5 \pm 8.37 \\
p=0.207\end{array}$ & $\begin{array}{c}5.61 \pm 5.2 \text { vs } 17.88 \pm 16.47 \\
p=0.03\end{array}$ & $\begin{array}{c}7.11 \pm 11.02 \text { vs } 9.88 \pm 9.73 \\
p=0.55\end{array}$ \\
\hline \multirow{3}{*}{\multicolumn{2}{|c|}{$\begin{array}{c}\text { Within group (MASD) } \\
\text { (Mean difference } \pm \text { Std. Error, } p \text { ) } \\
\text { Within group (SD) } \\
\text { (Mean difference } \pm \text { Std. Error, } p \text { ) }\end{array}$}} & T1-T2 & T2-T3 & T1-T3 \\
\hline & & $18.7 \pm 4.06, p=0.001$ & $-1.5 \pm 3.92, p=0.997$ & $17.2 \pm 3.4, p<0.001$ \\
\hline & & $-1.38 \pm 4.26, p=0.998$ & $8 \pm 4.1, p=0.2$ & $6.63 \pm 3.57, p=0.24$ \\
\hline \multicolumn{2}{|c|}{ CBQ overall } & $\begin{array}{l}\text { T1 - MASD vs. SD } \\
(\text { Mean } \pm \text { Std. Dev, } p)\end{array}$ & $\begin{array}{l}\text { T2 - MASD vs. SD } \\
(\text { Mean } \pm \text { Std. Dev, } p)\end{array}$ & $\begin{array}{l}\text { T3 - MASD vs. SD } \\
(\text { Mean } \pm \text { Std. Dev, } p)\end{array}$ \\
\hline
\end{tabular}

\begin{tabular}{|c|c|c|c|c|}
\hline $\begin{array}{l}\text { Within-time } \\
\text { Between-groups } \\
\text { Time x Group } \\
\end{array}$ & $\begin{array}{c}F(2,38)=32.26, \\
p<0.001, \eta_{p}^{2}=0.63 \\
F(1,19)=2.53, \\
p=0.13, \eta_{p}^{2}=0.11 \\
F(2,38)=1.66, \\
p=0.21, \eta_{p}{ }^{2}=0.08\end{array}$ & $\begin{array}{c}65.82 \pm 13.47 \text { vs } 71.4 \pm 10.1 \\
p=0.3\end{array}$ & $\begin{array}{c}51.55 \pm 9.03 \text { vs } 56.8 \pm 17.2 \\
p=0.39\end{array}$ & $\begin{array}{c}42.18 \pm 11.27 \text { vs } 55.6 \pm 17.63 \\
p=0.049\end{array}$ \\
\hline \multirow{3}{*}{\multicolumn{2}{|c|}{$\begin{array}{c}\text { Within group (MASD) } \\
\text { (Mean difference } \pm \text { Std. Error, } p \text { ) } \\
\text { Within group (SD) } \\
\text { (Mean difference } \pm \text { Std. Error, } p \text { ) }\end{array}$}} & T1-T2 & T2-T3 & T1-T3 \\
\hline & & $14.27 \pm 3.56, p=0.002$ & $9.36 \pm 3.33, p=0.033$ & $23.64 \pm 3.63, p<0.001$ \\
\hline & & $14.6 \pm 3.73, p=0.003$ & $1.2 \pm 3.49, p=.998$ & $15.8 \pm 3.8, p=0.002$ \\
\hline \multicolumn{2}{|c|}{ CBQ will power } & $\begin{array}{l}\text { T1 - MASD vs. SD } \\
(\text { Mean } \pm \text { Std. Dev, } p)\end{array}$ & $\begin{array}{l}\text { T2 - MASD vs. SD } \\
(\text { Mean } \pm \text { Std. Dev, } p)\end{array}$ & $\begin{array}{l}\text { T3 - MASD vs. SD } \\
(\text { Mean } \pm \text { Std. Dev, } p)\end{array}$ \\
\hline
\end{tabular}

\begin{tabular}{|c|c|c|c|c|}
\hline $\begin{array}{l}\text { Within-time } \\
\text { Between-groups } \\
\text { Time x Group }\end{array}$ & $\begin{array}{c}F(2,38)=25.25 \\
p<0.001, \eta_{p}{ }^{2}=0.57 \\
F(1,19)=2.73, \\
p=0.12, \eta_{p}{ }^{2}=0.12 \\
F(2,38)=1.15 \\
p=0.33, \eta_{p}{ }^{2}=0.057\end{array}$ & $\begin{array}{c}32.82 \pm 8.41 \text { vs } 36.6 \pm 6.34 \\
p=0.263\end{array}$ & $\begin{array}{c}23.55 \pm 5.5 \text { vs } 26.6 \pm 10.44 \\
p=0.406\end{array}$ & $\begin{array}{c}19.27 \pm 5.93 \text { vs } 27.2 \pm 11.26 \\
p=0.055\end{array}$ \\
\hline \multirow{3}{*}{\multicolumn{2}{|c|}{$\begin{array}{c}\text { Within group (MASD) } \\
\text { (Mean difference } \pm \text { Std. Error, } p \text { ) } \\
\text { Within group (SD) } \\
\text { (Mean difference } \pm \text { Std. Error, } p \text { ) }\end{array}$}} & T1-T2 & T2-T3 & T1-T3 \\
\hline & & $9.27 \pm 2.38, p=0.003$ & $4.27 \pm 2.13, p=0.177$ & $13.55 \pm 2.65, p<0.001$ \\
\hline & & $10 \pm 2.49, p=0.002$ & $-0.6 \pm 2.23, p=0.998$ & $9.4 \pm 2.78, p=0.009$ \\
\hline \multicolumn{2}{|c|}{ CBQ compulsive behaviour } & $\begin{array}{l}\text { T1 - MASD vs. SD } \\
(\text { Mean } \pm \text { Std. Dev, } p)\end{array}$ & $\begin{array}{l}\text { T2 - MASD vs. SD } \\
(\text { Mean } \pm \text { Std. Dev, } p)\end{array}$ & $\begin{array}{l}\text { T3 - MASD vs. SD } \\
(\text { Mean } \pm \text { Std. Dev, } p)\end{array}$ \\
\hline $\begin{array}{l}\text { Within-time } \\
\text { Between-groups } \\
\text { Time x Group }\end{array}$ & $\begin{array}{c}F(2,38)=7.51, \\
p=0.002, \eta_{p}^{2}=0.28 \\
F(1,19)=1.86, \\
p=0.19, \eta_{p}{ }^{2}=0.08 \\
F(2,38)=3.09, \\
p=0.049, \eta_{p}{ }^{2}=0.14\end{array}$ & $\begin{array}{c}19.55 \pm 3.78 \text { vs } 20 \pm 3.02 \\
p=0.766\end{array}$ & $\begin{array}{c}18.72 \pm 3.4 \text { vs } 19.4 \pm 4.53 \\
p=0.703\end{array}$ & $\begin{array}{c}13.91 \pm 4.44 \text { vs } 18.6 \pm 5.27 \\
p=0.039\end{array}$ \\
\hline \multirow{3}{*}{\multicolumn{2}{|c|}{$\begin{array}{c}\text { Within group (MASD) } \\
\text { (Mean difference } \pm \text { Std. Error, } p \text { ) } \\
\text { Within group (SD) } \\
\text { (Mean difference } \pm \text { Std. Error, } p \text { ) }\end{array}$}} & T1-T2 & T2-T3 & T1-T3 \\
\hline & & $0.82 \pm 1.37, p=0.998$ & $4.82 \pm 1.19, p=0.002$ & $5.64 \pm 1.4, p=0.002$ \\
\hline & & $0.6 \pm 1.45, p=0.998$ & $0.8 \pm 1.25, p=0.998$ & $1.4 \pm 1.47, p=0.997$ \\
\hline
\end{tabular}




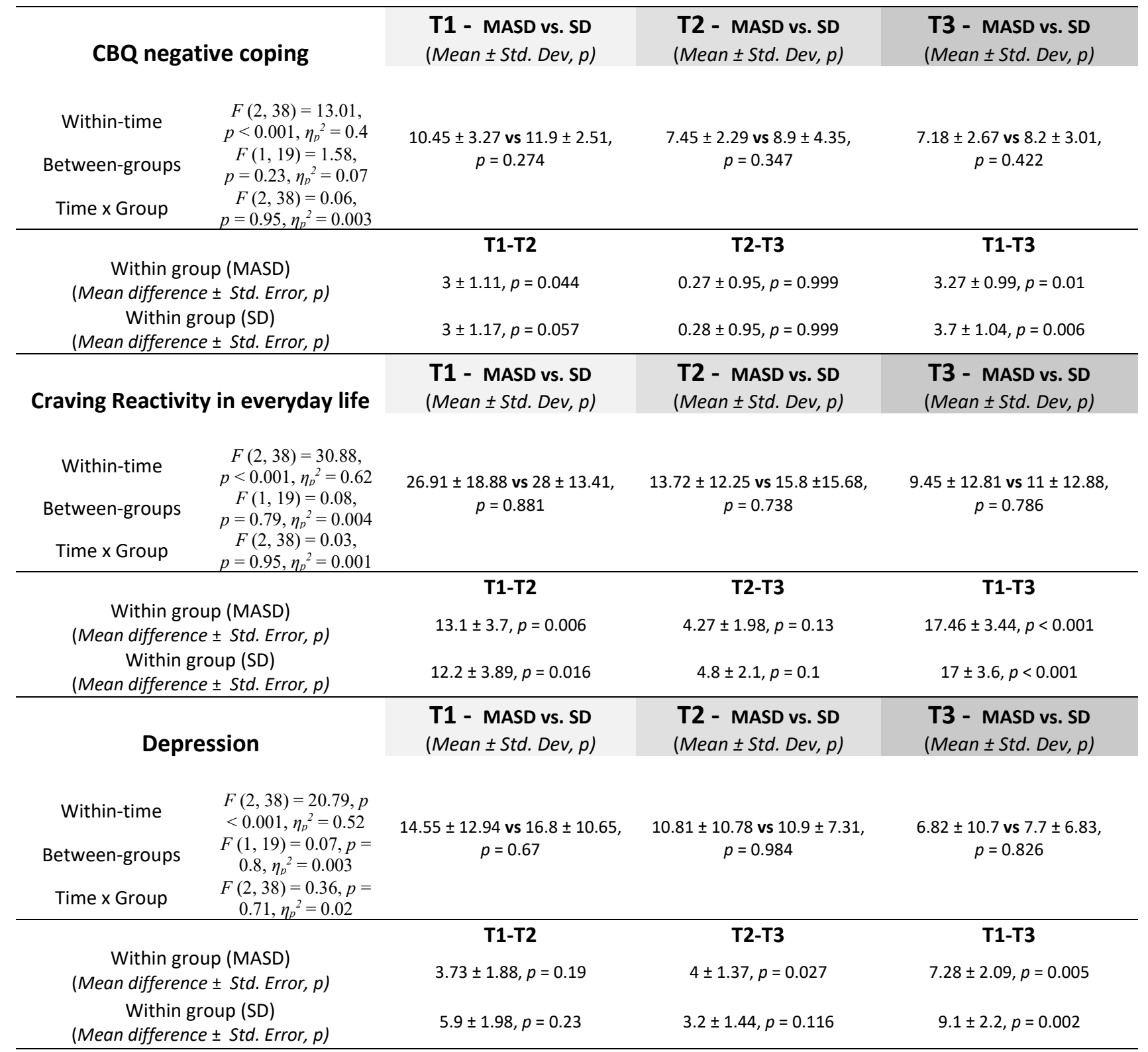




\section{FIGURES}

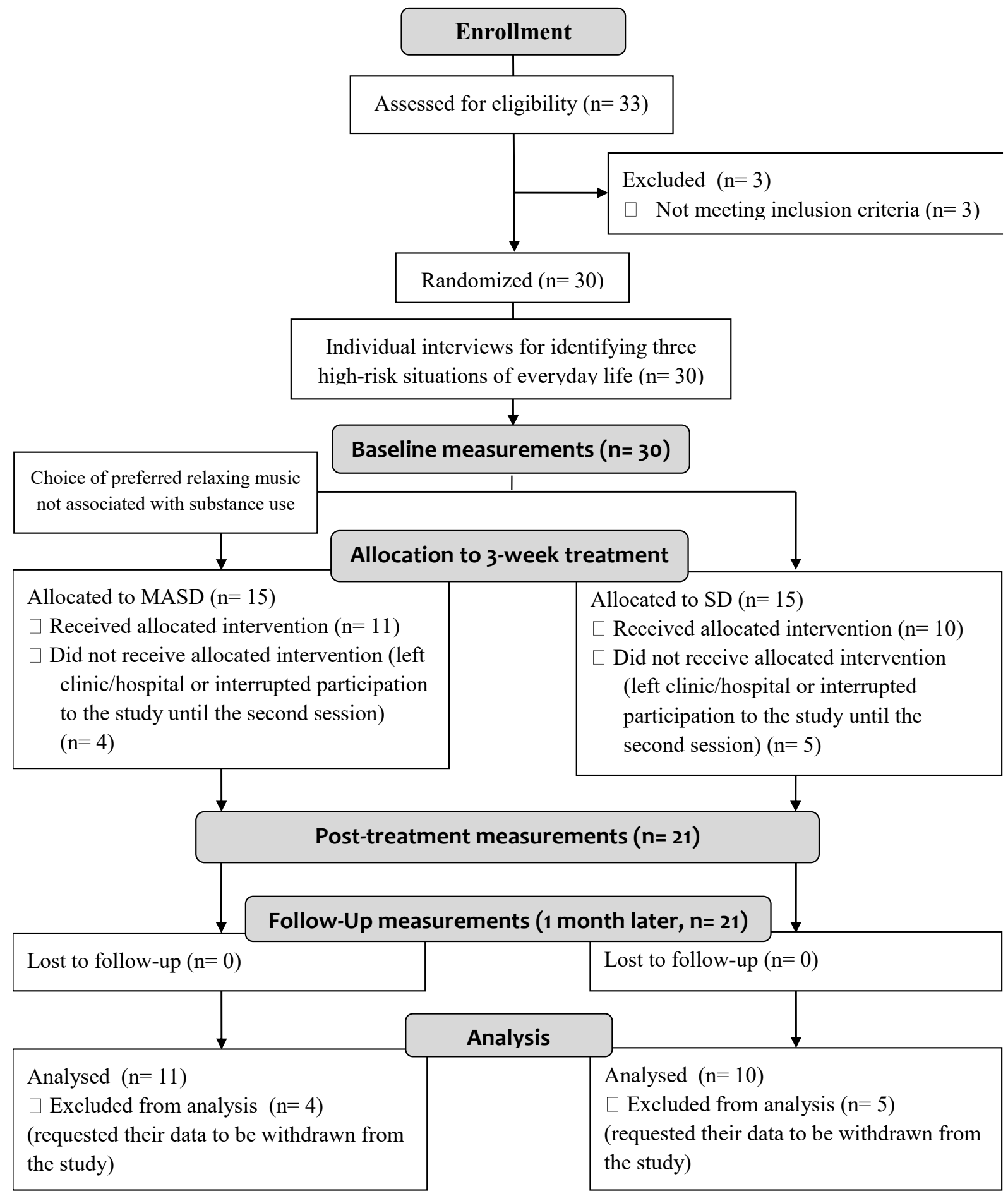

Figure 1. Diagram providing an overview of the two-armed study flow and participant intake and measurement time points. 

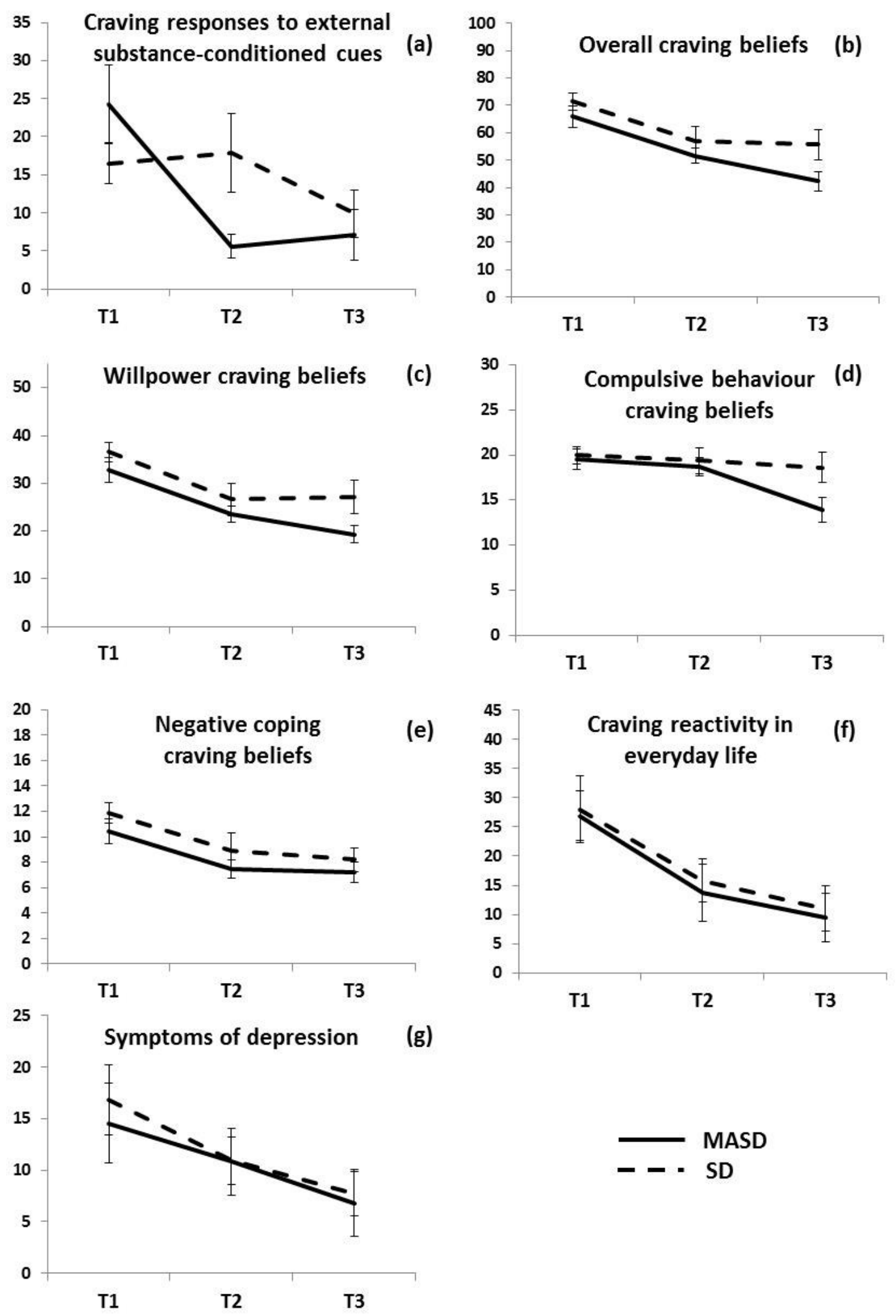

Figure 2. Graphic depiction of the factorial ANOVA interaction showing how MASD and SD changed differently over the three time points of the study. 


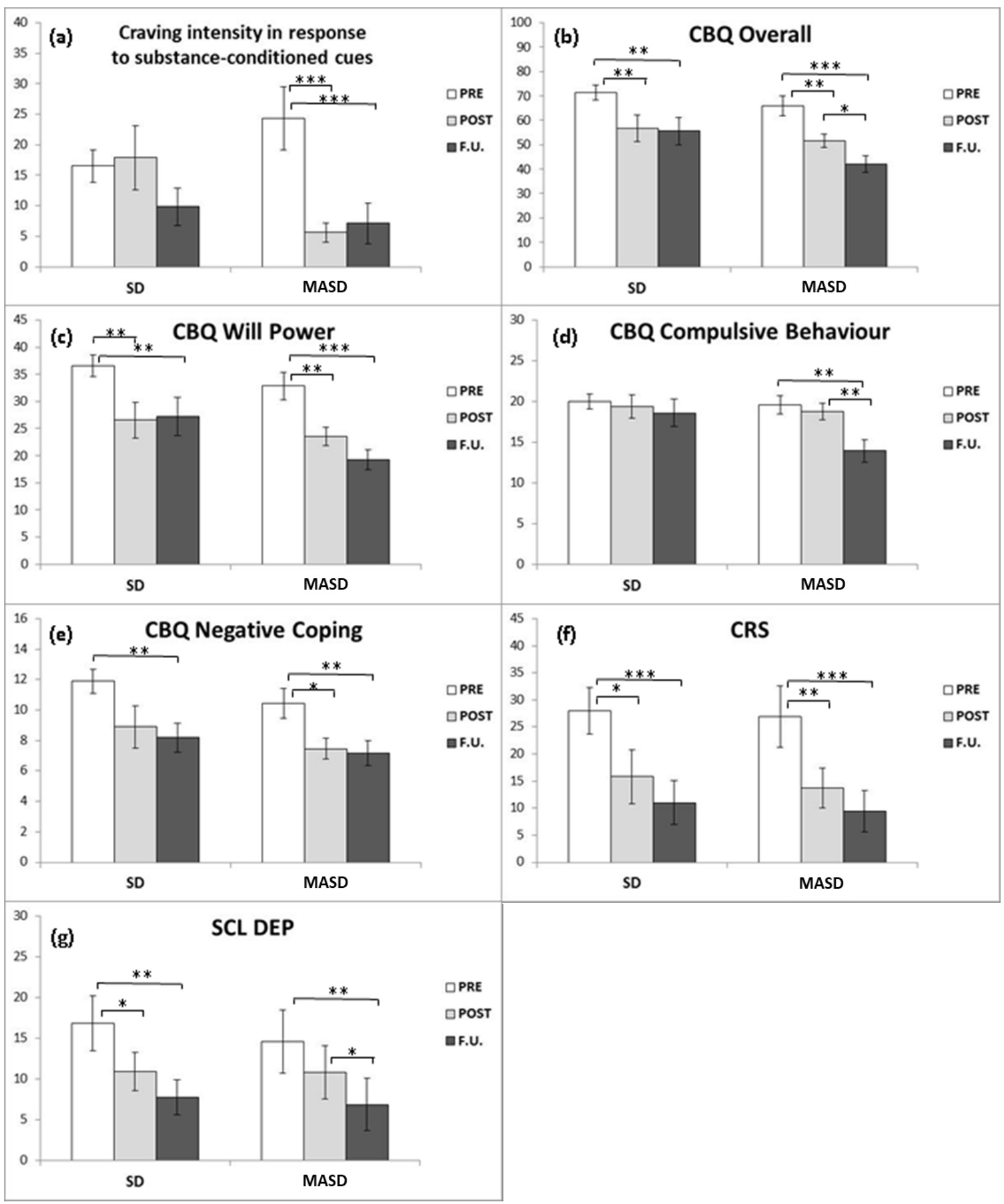

Figure 3. Graphic representation of MASD and SD changes that took place during the three time points of the study. Single asterisks $(*)$ indicate significant changes at the .05 level, double asterisks $(* *)$ indicate significant changes at the .01 level, and triple asterisks $(* * *)$ indicate significant changes at the .001 level. 


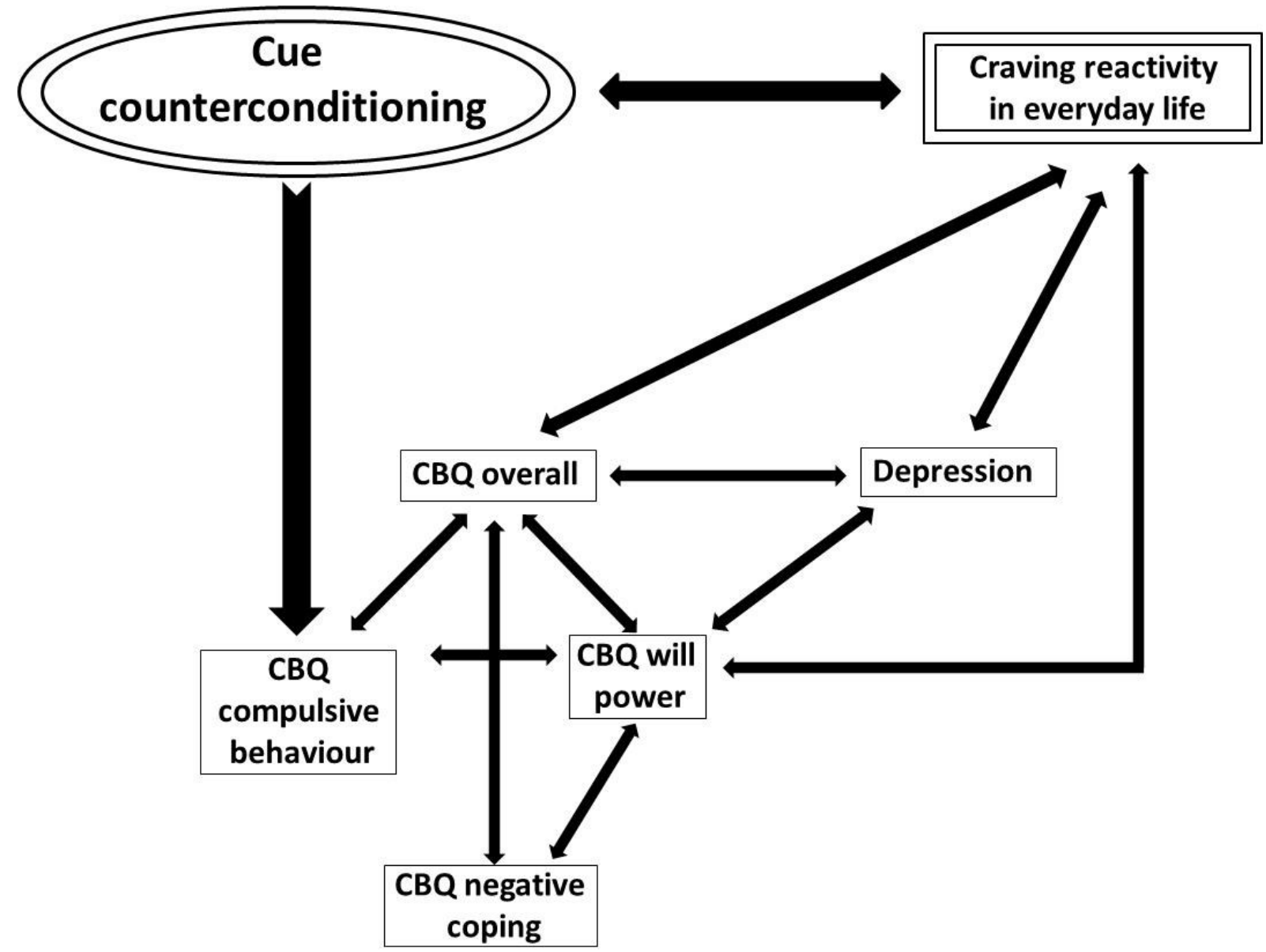

Figure 4. Illustration of the mechanisms by which MASD and SD treatment modalities appeared to influence the dependent variables of the study. The arrows indicate single or reciprocal influence between variables. 